\title{
ERRORES SISTEMÁTICOS EN EL DISEÑO CONSTRUCTIVO DE FACHADAS ${ }^{1}$
}

\section{(SYSTEMATIC MISTAKES IN THE CONSTRUCTIVE DESIGN OF FAÇADES)}

Juan Monjo Carrió, Dr. Arquitecto

Catedrático de la E.T.S. de Arquitectura de Madrid ESPAÑA

\section{RESUMEN}

El presente articulo lleva a cabo un recorrido analíticoconstructivo sobre algunos de los procesos patológicos más comunes en las fachadas de los edificios estudiando, desde el arranque de la fachada (zócalo) hasta su coronación (cornisa), las lesiones constructivas más llamativas, sus causas directas e indirectas, su reparación y, sobre todo, su prevención a nivel de diseño de detalle y de ejecución.

\section{SUMMARY}

This work tries to carry out a constructive analysis on some of the most common pathologic processes in the building façades, from the bottom (socle) to the top (cornice) studying the most outstanding constructive injuries, its causes, its repairings and, above all, its prevention at the detailing level as well as during the building process.

\section{INTRODUCCIÓN}

Si llevamos a cabo un análisis estadístico de la importancia relativa de las distintas partes de un edificio en las diferentes fases del proceso constructivo (desde la normativa hasta la ejecución, pasando por el proyecto) probablemente llegaremos a unos resultados similares a los que aparecen en el cuadro 1, donde se re- flejan unos datos estadísticos obtenidos de un modo esquemático a partir de unos pocos proyectos y obras de estos últimos años.

En él se toman como punto de partida los porcentajes de incidencia de 5 grandes unidades constructivas de un edificio (ESTRUCTURA, FACHADA, CUBIERTA, TABIQUERÍA-ACABADOS E INSTALACIONES) en sus

\section{CUADRO 1._IMPORTANCIA (\%) DE LAS DISTINTAS PARTES DE UN EDIFICIO EN LOS PROYECTOS}

\begin{tabular}{|c|c|c|c|c|c|c|c|}
\hline \multirow{2}{*}{$\begin{array}{l}\text { Parte del } \\
\text { edificio }\end{array}$} & \multicolumn{2}{|c|}{ Presupuesto } & \multirow{2}{*}{$\begin{array}{c}\text { Normas } \\
\text { NTE }\end{array}$} & \multicolumn{2}{|c|}{ Plie. de Cond. } & \multicolumn{2}{|c|}{ Planos } \\
\hline & N.P. & $R$. & & M. de V. & Part. & N.P. & $R$. \\
\hline Estructura & 26 & 20 & 31 & 27 & 16 & 26 & 20 \\
\hline Fachada & 23 & 15 & 14 & 21 & 7 & 10 & 12 \\
\hline Cubierta & 5 & 2 & 10 & 3 & 17 & 7 & 6 \\
\hline Tab. + Acab. & 29 & 36 & 15 & 16 & 22 & 9 & 15 \\
\hline Instalac. & 17 & 27 & 30 & 33 & 38 & 48 & 57 \\
\hline
\end{tabular}

\footnotetext{
${ }^{1}$ Este artículo está basado en la charla dictada por el autor en el Instituto Eduardo Torroja el dia 6-4-89 en el marco de los Seminarios sobre "Tecnologia de la Construcción y sus Materiales", organizados por ese Instituto.
} 
CUADRO 2.-CHEQUEO CONSTRUCTIVO DE LAS FACHADAS DE MADRID - DATOS PARCIALES Depto. de Construcción y Tecnología Arquitectónicas UPM

Fachadas observadas: 1.433 Lesiones anotadas: 1.462

\begin{tabular}{|l|r|l|c|c|l|c|}
\hline $\begin{array}{c}\text { Tipo de } \\
\text { lesión }\end{array}$ & $\%$ & \multicolumn{1}{|c|}{$\begin{array}{c}\text { Tipo de } \\
\text { material }\end{array}$} & $\begin{array}{c}\% \\
\text { observado }\end{array}$ & $\begin{array}{c}\% \\
\text { lesionado }\end{array}$ & $\begin{array}{c}\text { Unidad } \\
\text { constructiva }\end{array}$ & $\begin{array}{c}\% \\
\text { lesionadas }\end{array}$ \\
\hline Humedad & 13 & Lad. vist. & 22 & 11 & Zócalo & 11 \\
\hline Grieta & 7 & Enfosc. & 11 & 13 & Paño ciego & 26 \\
\hline Fisura & 9 & Revoco & 28 & 32 & Cornisa & 11 \\
\hline Despren. & 25 & P. ceram. & 2 & 3 & Barandilla & 6 \\
\hline Erosión & 8 & Metal & 5 & 8 & Balcón & 23 \\
\hline Eflores. & 5 & Piedra M. & 3 & 2 & Hueco & 7 \\
\hline Corrs. & 8 & Piedra Ch. & 11 & 10 & Mold. vert. & 3 \\
\hline Suciedad & 22 & H. in situ & 3 & 5 & Mold. horiz. & 8 \\
\hline Organis. & 3 & H. prefab. & 3 & 4 & Estruc. vista & 2 \\
\hline & & Pintura & 11 & 10 & Elem. suelto & 3 \\
\hline & & Madera & 1 & 2 & & \\
\hline
\end{tabular}

respectivos presupuestos, y se refleja su evolución en la Normativa, por un lado, y en dos de los documentos más descriptivos técnicamente del proyecto, como son sus pliegos de Condiciones y sus Planos que, a su vez, son los documentos más importantes desde el punto de vista jurídico.

Pues bien, es fácil observar una pérdida de la importancia relativa de dos de las cinco unidades en favor, sobre todo, de otra de ellas, tanto en la normativa, como en los documentos de proyecto, sobre todo en los planos; y ello ocurre, tanto en obras de nueva planta (N. P.) como en las de reforma y rehabilitación (R.). En definitiva, esto nos lleva a pensar que puede existir una falta de definición en los documentos de proyecto y en la normativa normalmente utilizada (NTE y NBE) de estas unidades. Dichas unidades, como se puede observar, son las de FACHADA por un lado, y la de TABIQUE. RIIA-ACABADOS por otra, mientras que la unidad que sale beneficiada es la de INSTALACIONES.

El resultado de esta falta de definición suele ser una ejecución deficiente de esas unidades, pues el "ejecutor" (el obrero, incluso, especialista) tiene que basarse en sus propios conocimientos (no siempre técnicos), en su experiencia (lo que se viene llamando "la buena práctica de la construcción", aunque muchas veces no sea tan buena) o en su intuición, con la que tiene que suplir la falta de especificaciones, aunque a la larga no asuma la responsabilidad técnica que, en definitiva, acaba recayendo en el proyectista o en el director de la obra.
La consecuencia final de esa ejecución deficiente es la aparición de un proceso patológico, que acaba en diversas lesiones constructivas que deterioran tanto la integridad físico-química de la unidad en cuestión, como su apariencia estética. El que sale perjudicado, a la larga, es el propio edificio y sus ocupantes, además del entorno urbano en el que el edificio se orienta.

Para comprobar los diferentes aspectos de esta afirmación, el cuadro 2 recoge unos datos parciales de un estudio que se está llevando a cabo, bajo la dirección del autor, en el Departamento de Construcción y Tecnología Arquitectónicas de la U.P.M. (Escuela T.S. de Arquitectura), en el que se realiza un "chequeo constructivo" de las fachadas de la ciudad de Madrid². En el cuadro se puede ver, por una parte, la distribución porcentual de los 9 tipos de lesiones consideradas, en la que destacan los desprendimientos y las suciedades. Por otra, los 11 tipos de materiales observados, en general, y lesionados, en particular, destacando la debilidad que presentan los enfoscados y revocos. Por último, las 10 unidades constructivas en que se ha descompuesto una fachada y el porcentaje de incidencia de su proceso patológico en el total de casos estudiados. En este último grupo, el que más nos interesa para el presente trabajo, destacan como más lesionados los paños ciegos y los balcones, seguidos por zócalos y cornisas y, finalmente, por huecos, barandillas y molduras horizontales.

${ }^{2}$ Este trabajo está descrito en un articulo aparecido en el $n .^{\circ} 396$ de la revista "Informes de la Construccion" de julio-agosto/88. 
Precisamente, estos últimos datos estadísticos nos dan pie para analizar una serie de casos concretos en los que aparecen errores sistemáticos de diseño y construcción de ciertas unidades constructivas, lo que es objeto de este artículo.

En efecto, las unidades que se destacan por su alto porcentaje de lesiones son: o las más abundantes (caso de los paños ciegos), o las más expuestas a agentes atmosféricos y mecánicos (cornisas y zócalos respectivamente), o las que presentan más superficie de exposición y más "recovecos" en su diseño (huecos y molduras). En definitiva, las que requieren mejor estudio constructivo (diseño), más cuidada elaboración (ejecución) y más atención durante su vida (mantenimiento), con objeto de conferirles mayor integridad físicoquímica.

En todas ellas, pues, su definición a nivel de proyecto es clave, tanto para especificar su calidad, como para condicionar su ejecución, sin olvidar la importancia de un mantenimiento cuidado. De lo contrario, la amenaza de su lesión patológica es inminente.

Por todo ello, parece indicado ese análisis de una serie de casos concretos, que no pretende ser exhaustivo, pero sí demostrativo de la importancia del diseño constructivo previo a través de las consecuencias originadas por la falta del mismo. En general, se trata de unidades constructivas muy comunes, cuya falta tradicional de diseño y especificaciones las empuja a un modo "práctico" de ejecutarlas que, sin embargo, es equivocado, aunque se sigan aparentemente las "buenas normas" de la construcción. Veamos:

\section{ANÁLISIS DE CASOS}

Siguiendo una línea ascendente en una sección típica de fachada de varias plantas (Fig. 1) analizaremos 7 unidades constructivas concretas, con algunas de las manifestaciones patológicas más usuales en ellas.

\subsection{Zócalo o arranque de fachada (Fig. 2)}

Aunque es un proceso patológico muy evidente, quiero hacer mención de dos aspectos del mismo que no se consideran lo suficiente.

\subsubsection{La humedad de capilaridad (Fig. 2.a)}

Normalmente se tiene en cuenta el peligro de la humedad capilar que asciende desde los cimientos, por lo que empieza a ser corriente la colocación de barreras, impermeables horizontales para evitarla, pero no se considera, en la mayoria de los casos, la humedad proviniente de la acera adosada al zócalo, como con(C) Consejo Superior de Investigaciones Científicas

Licencia Creative Commons 3.0 España (by-nc)

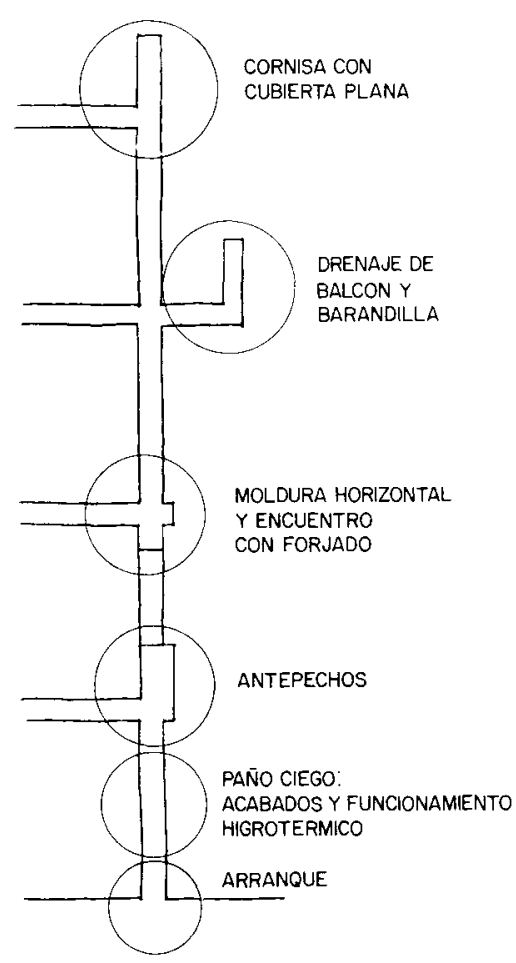

Fig. 1.-Algunos puntos a estudiar.

secuencia del agua de lluvia combinada con el viento. Ésta acaba filtrándose por la fisura que forzosamente aparece en el ángulo diedro del encuentro entre acera y pared y, si el material del zócalo es capilar (tanto el exterior como el soporte), la ascensión del agua es inevitable, provocando, además, erosiones por heladas.

La figura nos da una idea para completar la barrera impermeable horizontal con una banda vertical detrás de un rodapié ejecutado con material poco capilar. (Hay que pensar que el revoco es normalmente más capilar que la mayoría de las piedras naturales o que las piezas prefabricadas de hormigón).

Las fotos de la figura 3 nos muestran casos muy claros de humedad capilar en zócalos de revoco.

\subsubsection{La erosión mecánica (Fig. 2.b)}

Además de la erosión física por la helada del agua capilar, es muy corriente en los zócalos la erosión mecá. nica producida por continuos golpes y roces de personas y todo tipo de objetos duros en contacto esporádico con esa zona, acompañada del inevitable ensu. ciamiento. Sin embargo, a pesar de ser una lesión muy común y, por tanto, muy predecible, pocas veces se realiza un diseño adecuado que evite este proceso patológico, y no sólo en exteriores, sino también en interiores; icuántos locales públicos (por ejemplo, colegios) tienen los zócalos de sus tabiques sin ninguna protección!

http://informesdelaconstruccion.revistas.csic.es 

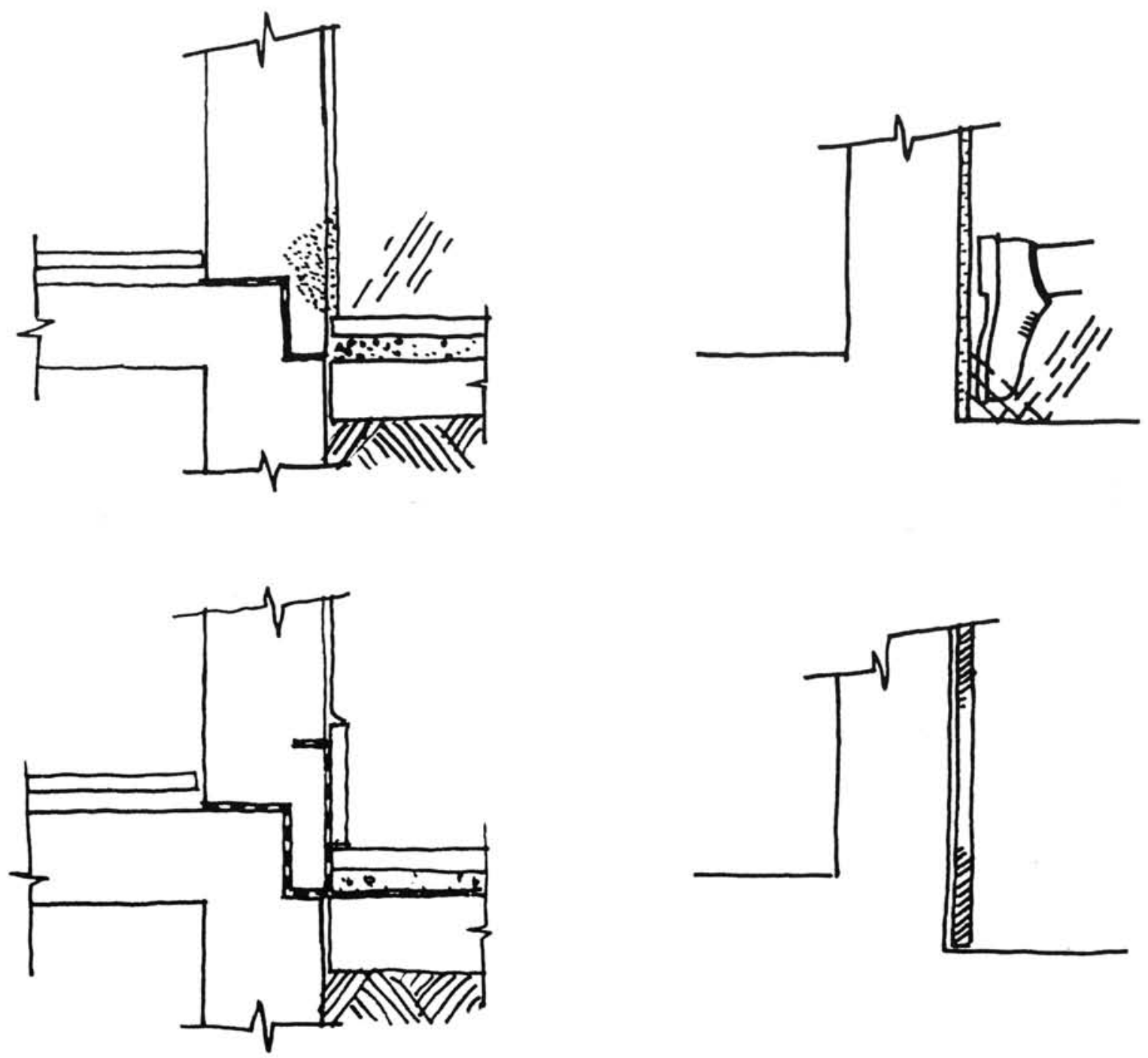

CAPILARIDAD (2.a)

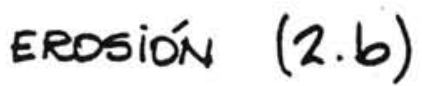

Fig. 2.-Arranque de fachada.
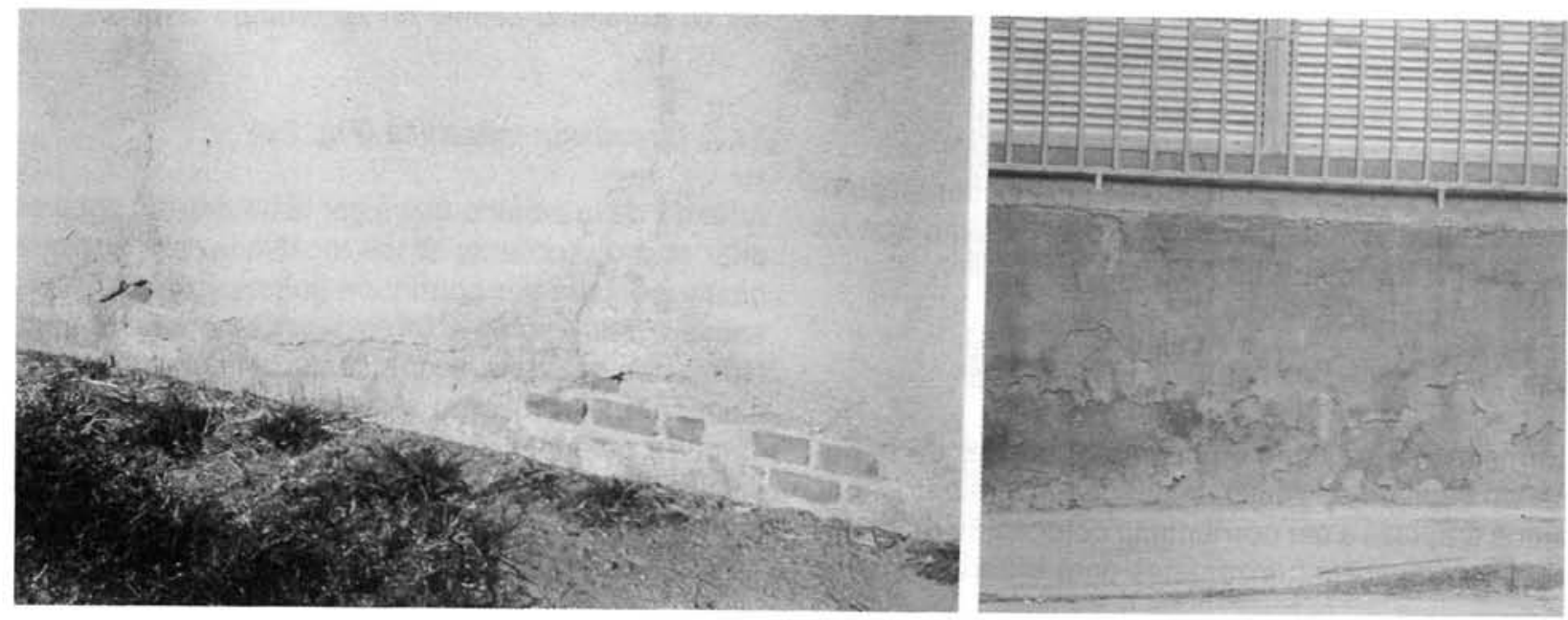
La prevención pasa, como es tradicional, por colocar, en los zócalos, con la altura necesaria, materiales que, por una parte, sean resistentes a roces e impactos, según la zona, y, por otra, sean de acabado "recuperable", bien por simple lavado, bien por procesos de pulido, para no tener que recurrir a la pintura como solución provisional.

\subsection{Encuentro estructura-cerramiento (Fig. 4)}

Los dos errores del punto anterior, aunque bastante corrientes son, sin embargo, fácilmente asumibles como tales y, por tanto, corregibles con un poco de atención en el diseño y en la ejecución. El que hace referencia a este punto, por el contrario, no es todavía asumido como error y por tanto de difícil corrección; por ello cabe detenerse algo más en él.

Las fachadas de fábrica (sobre todo las de ladrillo visto o revocado) tienen una larga tradición en los países mediterráneos, $\mathrm{y}$ han sabido mantenerse vigentes a lo largo de los siglos. Lo han hecho en su aspecto formal, pero no, ciertamente, en el constructivo. En efecto, un muro de fábrica era, tradicionalmente, un muro de carga que recibía el apoyo de los forjados de los diferentes pisos, además de las partes superiores del propio muro y que, por tanto, quedaba directamente esta- bilizado por la compresión, siempre que gozara de suficiente sección como para evitar el pandeo.

Las actuales fachadas de fábrica de ladrillo, por lo ge neral, no constituyen muros de carga y, como consecuencia, no reciben el apoyo de los forjados sino que, por el contrario, se apoyan en ellos, y de ahi nace el problema.

Por una parte, al no ser muro de carga, sufre un adelgazamiento importante hasta llegar al $1 / 2$ pie. Al no recibir, además, más carga que su propio peso, el muro resulta inestable ante cualquier acción mecánica que se salga de lo razonablemente previsto ${ }^{3}$. Ello introduce la posibilidad de flexiones excesivas por esfuerzos de viento o pandeos importantes al flechar los forjados y cargar sobre la fachada, todo lo cual redunda en grietas y fisuras de todo tipo.

Esta falta de estabilización facilita, asimismo, la aparición de grietas, consecuencia de dilataciones y contracciones térmicas del propio muro sometido directamente a grandes cambios de temperatura por exposición directa.

${ }^{3}$ Véase el trabajo de Simpson, Gumpertz y Heger aparecido en el número de marzo de 1989 de ARCHITECTURAL RECORD bajo el titulo "Aveneer too thin?"
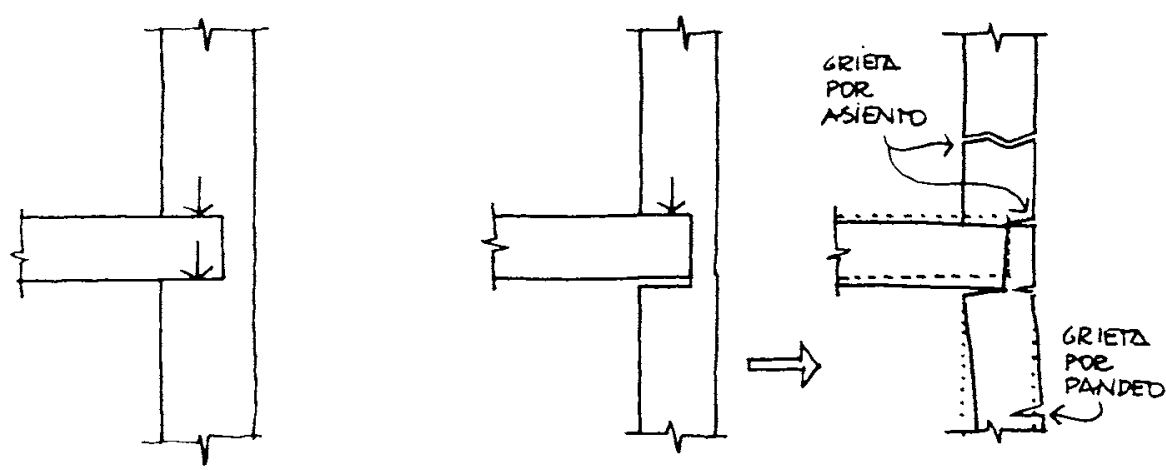

MURO DE CARGA (ESTABILIZADO)

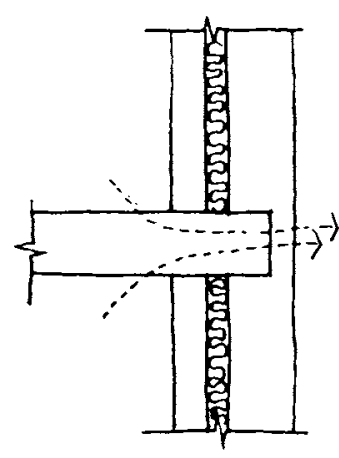

PUENTE TEEMIOO
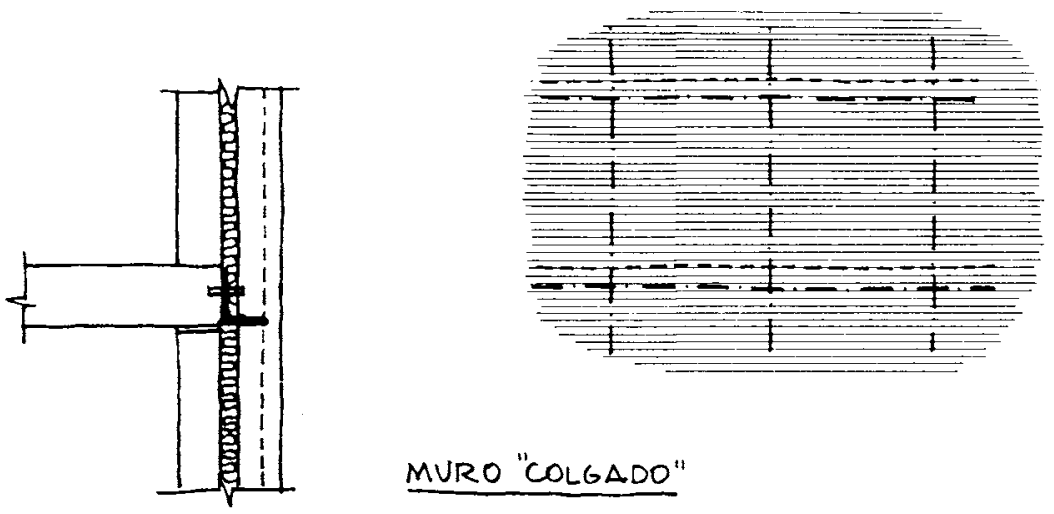

MURO "COLGADO"

Fig. 4.-Encuentro estructura-cerramiento. 

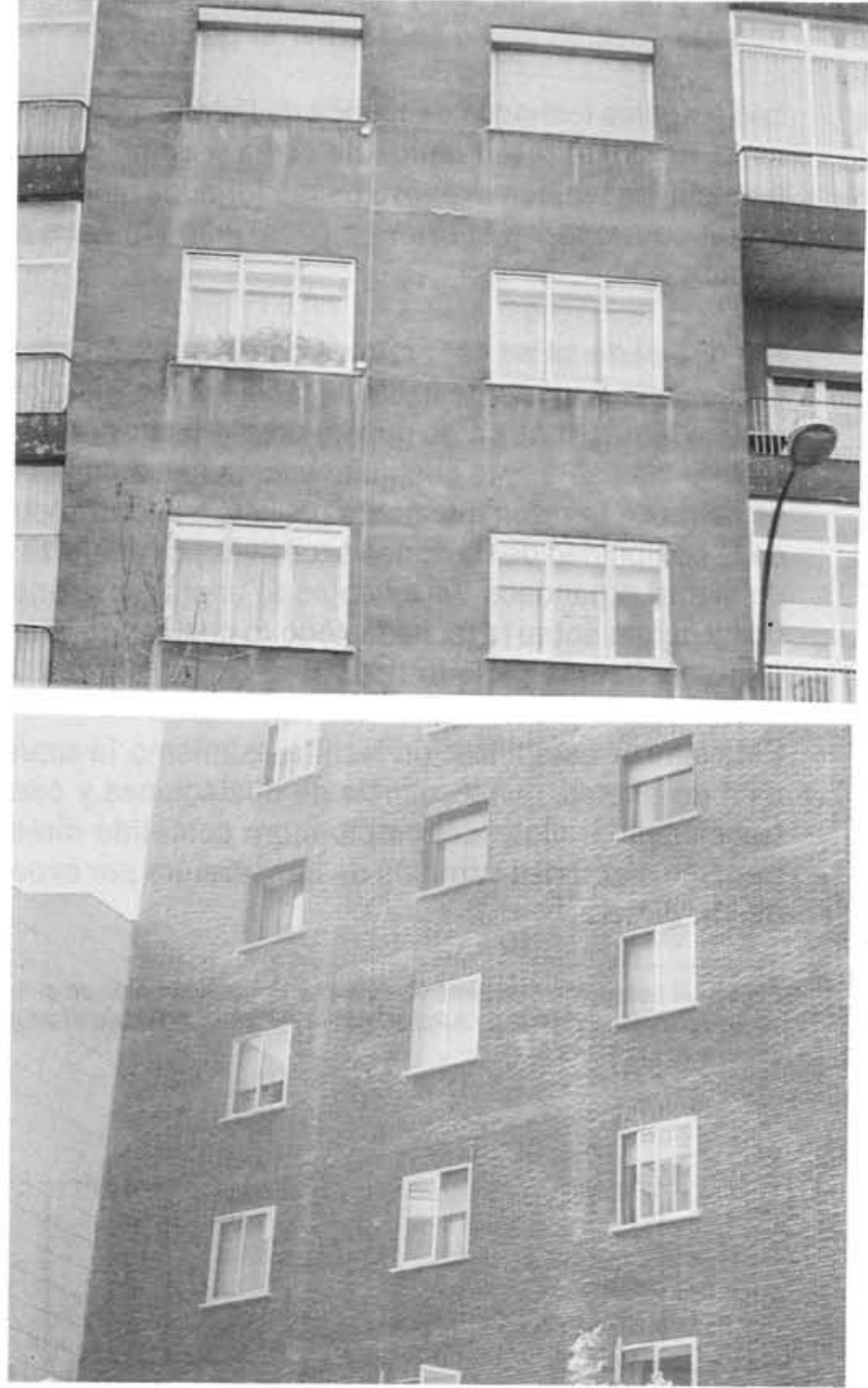

$5 a$

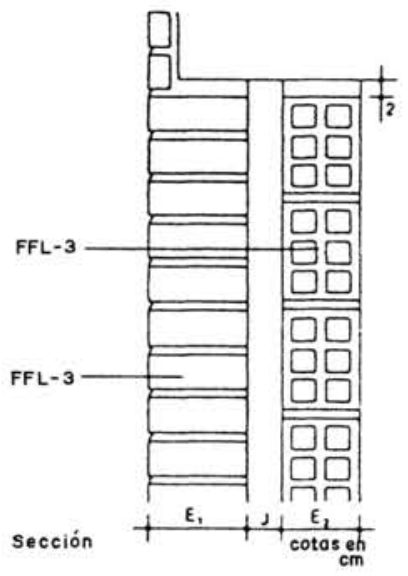

$5 b$

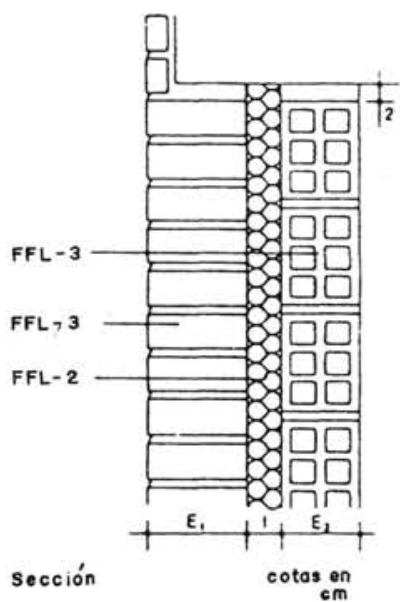

$\underset{\mathrm{cm}}{\mathrm{em}}$
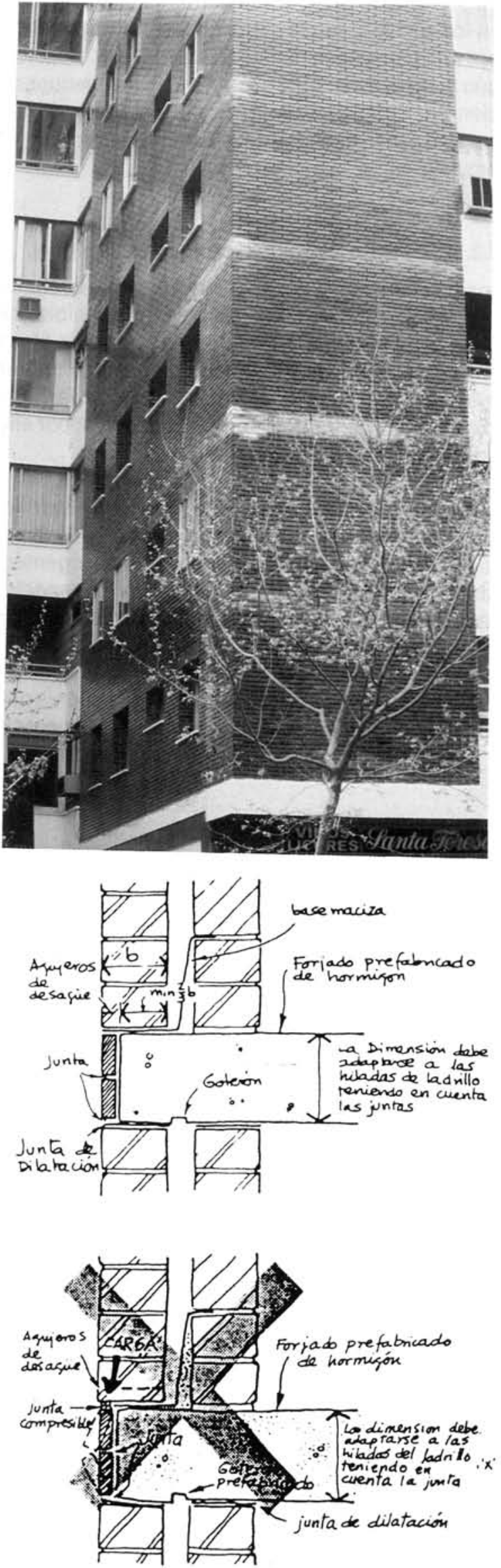

Fig. 5.-Esquemas incluidos en la NTE FFL y otras publicaciones. 
Por otra parte, la carga de las fachadas en el borde de los forjados puede producir (y produce, en ocasiones) flechas en los mismos, con los consiguientes asientos, por la parte superior, y pandeos, por la parte inferior, con nueva aparición de grietas, normalmente horizontales (Fig. 4).

Por último, y éste es quizás el punto más débil de la solución convencional, la necesidad de superficie de apoyo para la fábrica hace volar la estructura horizontal (normalmente sobresale también la vertical) más allá del eje del muro, provocando, por un lado, una disminución de la sección del muro frente a los elementos estructurales, que lo debilita (el $1 / 2$ pie se convierte en una plaqueta) y, por otro, un puente térmico prácticamente inevitable (ver fotos de la figura $5 a$ ).

Esta "triada problemática" (falta de estabilización por carga, posibles asientos y pandeos y puente térmico) hacen totalmente rechazable la solución normalmente utilizada que, por ello, se convierte en un "error sistemático" de diseño constructivo sin aparente alternativa, refrendada, sin embargo, por multitud de publicaciones e, incluso, de normativa (Fig. 5b).

No obstante la solución existe, incluso dentro de los muros de fábrica, y no es nueva. Consiste en contemplar dicho muro constructivamente no como "apoyado", sino como "colgado" y resolver su diseño como hacemos con los Ilamados "muros cortina". Ello exige, naturalmente, dos condiciones:

- Por una parte, una estructura auxiliar de anclaje del muro a la estructura del edificio, lo suficientemente resistente como para no afectar a la integridad de la fábrica, teniendo en cuenta su constitución por unidades ensambladas con mortero.

- Por otra, la independencia térmica entre el muro y la estructura para anular los posibles puentes térmicos así como la transmisión de esfuerzos térmicos, tanto de la estructura a la fábrica, como a la inversa. En definitiva, que el muro sea una verdadera "piel" del edificio.

La estructura auxiliar puede ser muy variable, desde una completa, formada por montantes verticales y elementos horizontales de apoyo, todo ello unido a la estructura del edificio por medio de rótulas en puntos clave, hasta la más simple, a base de elementos metálicos horizontales adosados a los frentes de forjado, asegurando flechas absolutas de éstos por debajo de los 5 milimetros.

\subsection{Paño ciego}

También interesa comentar dos aspectos. Uno se refiere a su constitución y otro a su acabado exterior.

\subsubsection{Funcionamiento higrotérmico de un paño ciego} (Fig. 6)

El aspecto higrotérmico entre los objetivos funcionales de una fachada es, desde el punto de vista constructivo, uno de los más importantes, afectando, por tanto, a su diseño, a su ejecución y a su mantenimiento. Por otra parte, es uno de los temas de moda en las últimas publicaciones al respecto, incluso en la normativa exigencial; sin embargo, en la edificación cotidiana, es difícil encontrar un proyecto en el que se haya llevado a cabo un estudio del funcionamiento higrotérmico del cerramiento elegido, aunque sea somero. Los proyectistas acaban en el lugar común de las "fachadas convencionales" (desde el punto de vista constructivo) sin preocuparse demasiado de esa funcionalidad higrotérmica, o dando por sentado su buen funcionamiento por el simple hecho de ser las que más se usan.

Por ello, me parece importante destacar el error sistemático que se comete en este sentido con algunos tipos de cerramientos en determinadas zonas climáticas, por no tener el espíritu crítico y analítico suficiente como para comprobar, aunque sea a nivel teórico, su correcta funcionalidad.

Quizás el caso más claro, y uno de los más extendidos, sea el de las fábricas de ladrillo (1 pie y $1 / 2$ pie) trasdosadas interiormente por medio de una plancha aislante y un tabique de ladrillo hueco sencillo.

No pretendo entrar en los cálculos de gradientes de temperatura o de presión de vapor en el espesor del cerramiento, cálculos que, por otra parte, están ya en muchos manuales, pero sí me parece interesante hacer un breve análisis para comprender el error sin necesidad de entrar en ellos.

En las soluciones constructivas mencionadas (Fig. 6.a), el hecho de tener el aislante muy cerca del interior hace que en invierno haya un salto brusco de temperatura en el espesor del cerramiento, cerca de su cara interior, donde todavía la presión del vapor es alta y, por tanto, la temperatura de rocío fácilmente alcanzable. Ello trae, como consecuencia, altas posibilidades de condensación intersticial en la cara exterior de la plancha aislante que, además de anular su efecto como tal, produce lesiones secundarias al tratar de salir la humedad hacia el exterior, tales como eflorescencias, erosiones, organismos, etc. (ver fotos Fig. 6.c).

En este sentido, es de todos conocido el doble remedio de colocar el aislante lo más afuera posible, o in. troducir una barrera de vapor en la cara caliente de dicho aislante si lo tenemos que situar hacia el interior; sin embargo, esto implica salirse del modo de hacer convencional y, por tanto, romper una "inercia de diseño y ejecución" que resulta muy difícil. 


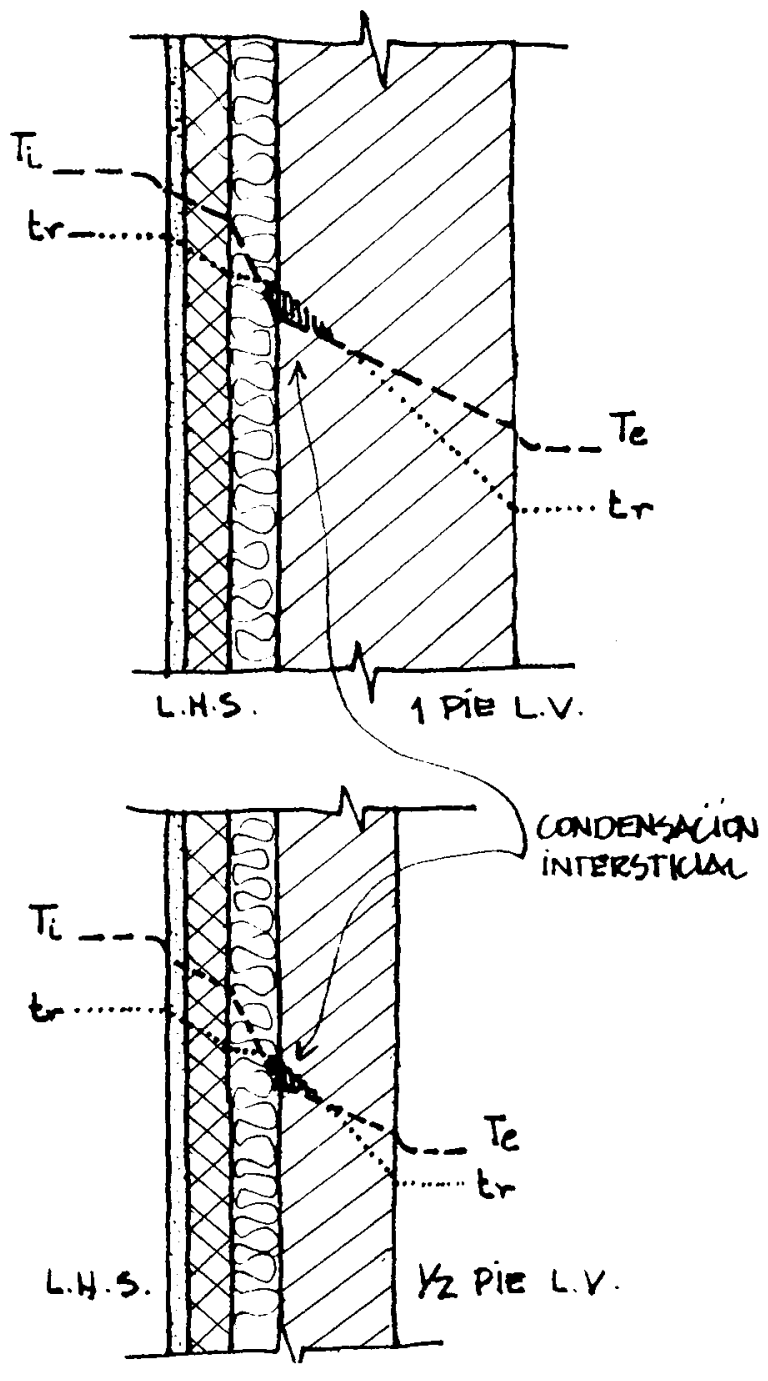

Fig. 6a.-Fachadas corrientes.

Naturalmente, el diseño correcto de un cerramiento, desde el punto de vista higrotérmico, exige el estudio previo de las condiciones ambientales y de uso, interiores y exteriores, en cada caso, por lo que sería absurdo tratar de dar, ahora, soluciones a todos ellos. Sin embargo, me atrevo a apuntar dos de ellas, con carácter general, para resolver, por lo menos, los casos más frecuentes (Fig. 6.b).

Para las fachadas de $1 / 2$ pie de ladrillo visto, trasdosar al interior con:

- enfoscado de la cara interior del $1 / 2$ pie,

- plancha de aislante (con o sin barrera de vapor),

- 1/2 pie de ladrillo LHD acabado por su interior.

De ese modo conseguiremos situar algo más al exterior el aislante, alejando el peligro de condensación intersticial, además de ganar inercia térmica al interior.

Para las fachadas de ladrillo revocado al exterior:

\section{Funcionamiento higrotérmico}
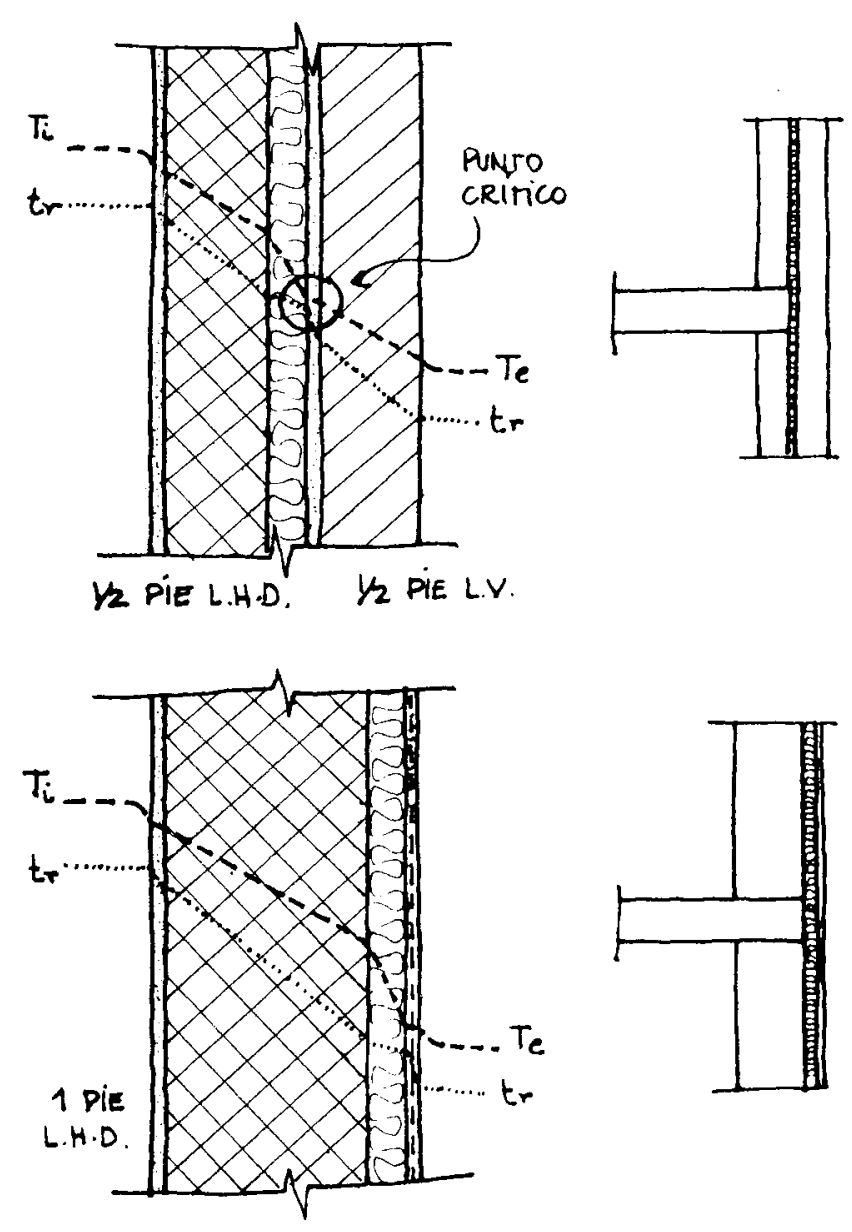

Fig. 6b.-Fachadas propuestas.

- 1 pie de ladrillo LHD acabado por su interior (puede llegar a $1 / 2$ pie, sobre todo en paredes medianeras),

- plancha de aislante semirrígido por fuera,

- revoco armado al exterior.

Cualquiera de estas dos soluciones, por otro lado, permiten dar continuidad al aislante por delante de los elementos estructurales, tal como veíamos en el punto 2.3., evitando asi los puentes térmicos.

Todos estos comentarios se refieren a la situación de invierno. También la situación de verano implica errores sistemáticos, el más destacado, quizás, el de las cubiertas sin cámara de aire (las llamadas "calientes" paradójicamente) al no considerar la temperatura superficial exterior real, consecuencia de la radiación solar directa. Error éste, que, en cierto sentido, puede considerarse inducido por la propia norma NBE-CT, que hace partir los cálculos del $\mathrm{k}$, de la temperatura exterior, $T_{e}$, en lugar de la superficial exterior, $t_{e}$, que, como sa- 


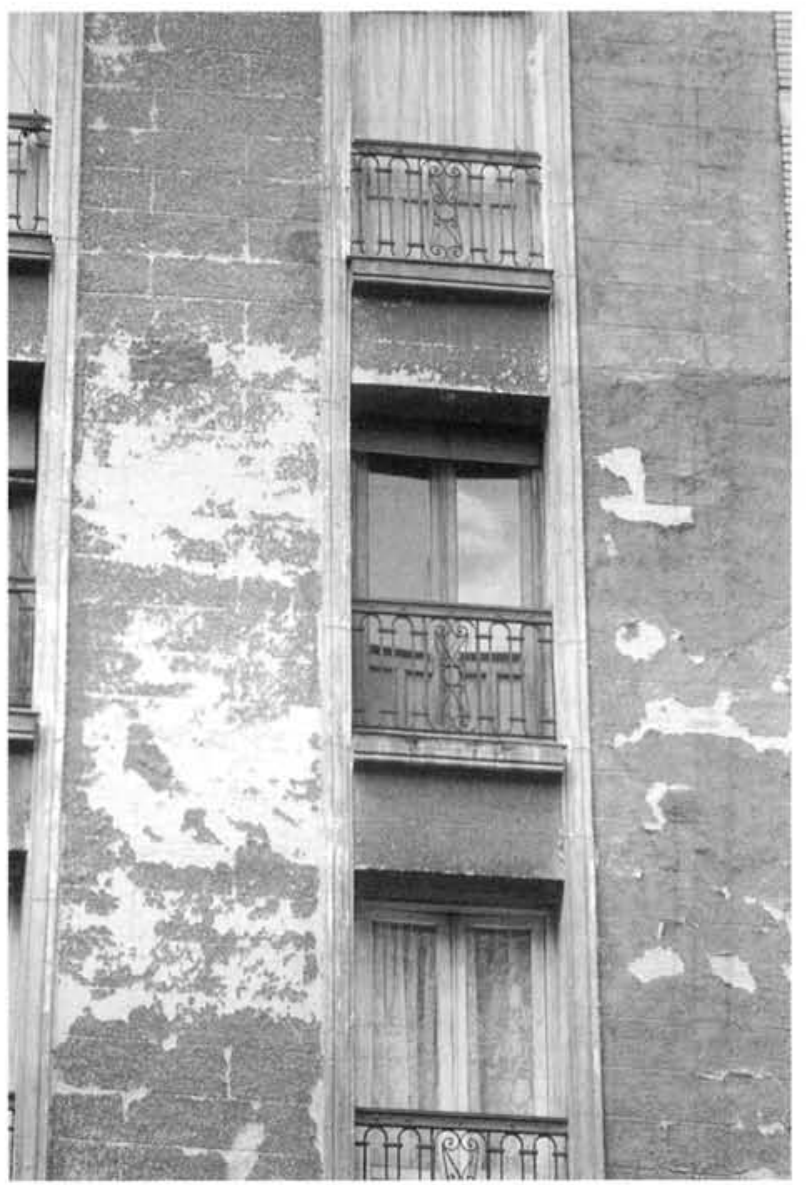

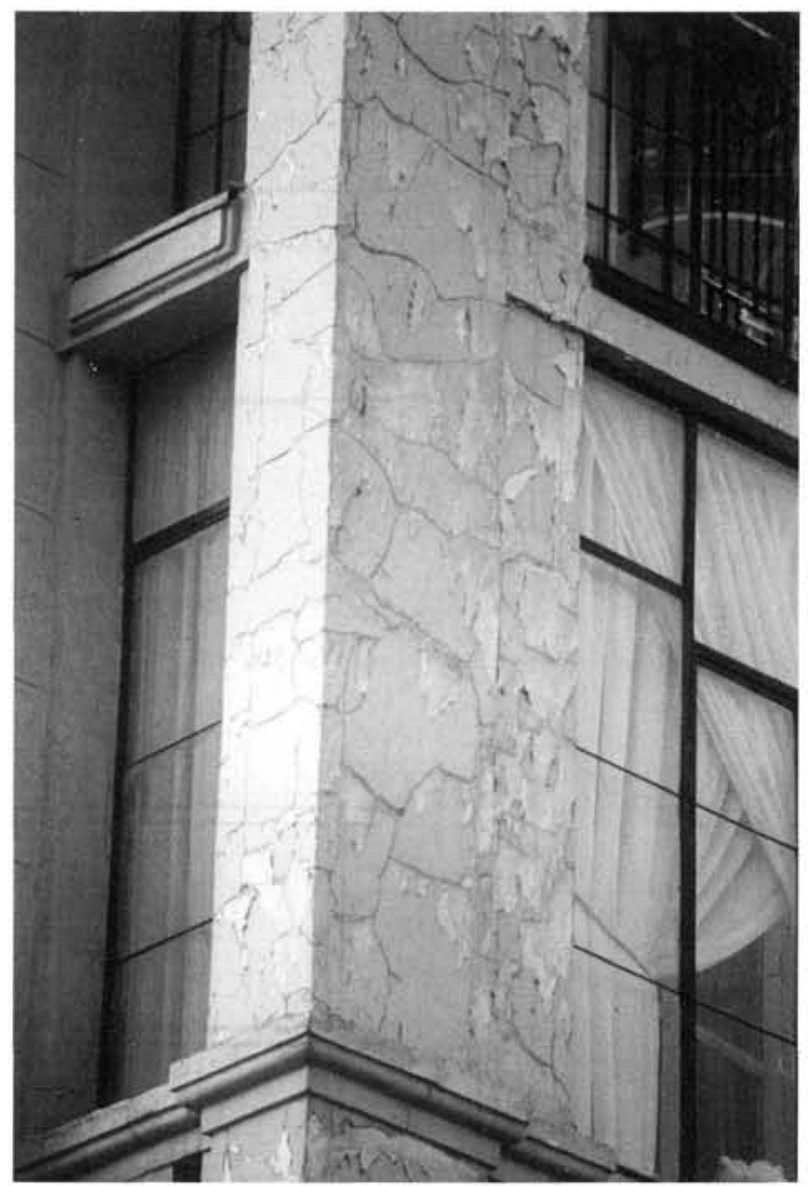

Fig. 6.c

bemos, no tienen ninguna relación cuando la superficie exterior recibe la radiación solar directa.

Pero ese es un error que dejaremos para otra ocasión; quizás al hablar de cubiertas.

\subsubsection{Desprendimiento de alicatados exteriores}

Los acabados exteriores de las fachadas son, siempre, las partes de las mismas más atacadas por las inclemencias atmosféricas y, por tanto, las más susceptibles de sufrir un proceso patológico.

La mayoria de acabados exteriores, sean continuos o por elementos, sufren también errores sistemáticos en su diseño y ejecución, pero ahora me interesa destacar uno, especialmente, por la misma razón de la "tradición constructiva errónea" que está llevando, incluso, a la eliminación de su uso en fachadas como consecuencia de los repetidos fracasos por desprendimiento. Me refiero a los alicatados exteriores median- te plaqueta cerámica, acabado, por demás, muy tradicional en extensas zonas de nuestro país.

Si observamos la figura 7.a, veremos que el sistema tradicional de alicatar un paño a base de colocar la pellada de mortero en el dorso de la plaqueta tiene, como consecuencia, entre otras, la falta de continuidad del mortero de agarre en todo el paño, con interrupciones coincidentes con las puntas de las plaquetas. Esto lo observamos continuamente cuando nos encontramos con paños de alicatados desprendidos, como muestra la figura 8.

Este hecho, aparentemente tan simple, tiene tres consecuencias de fallo constructivo que concluyen en el posible desprendimiento de la plaqueta. Veamos:

- Por una parte, el mortero está en contacto con la pieza sólo en la parte central de su cara dorsal, por lo que la adherencia entre los dos elementos cons. tructivos se basa en la resistencia a la tracción de las pequeñas penetraciones de mortero en los re- 


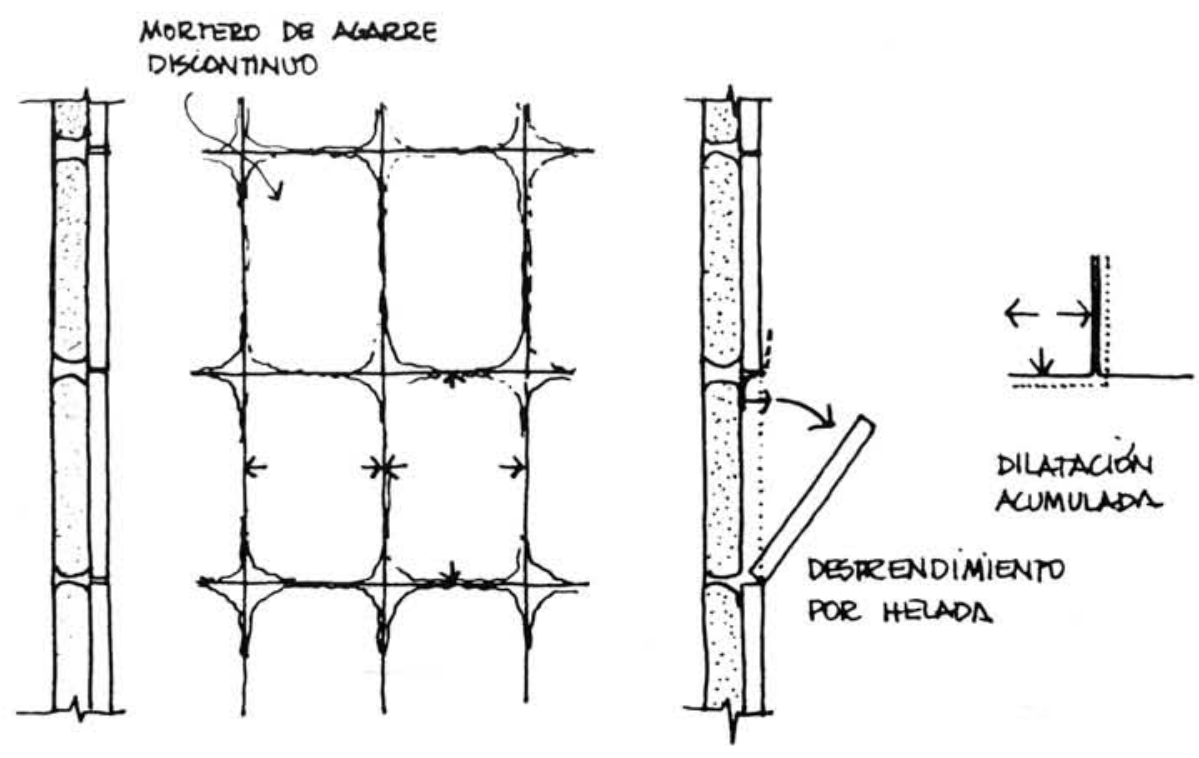

Fig. 7.a.-Alicatado "a hueso".
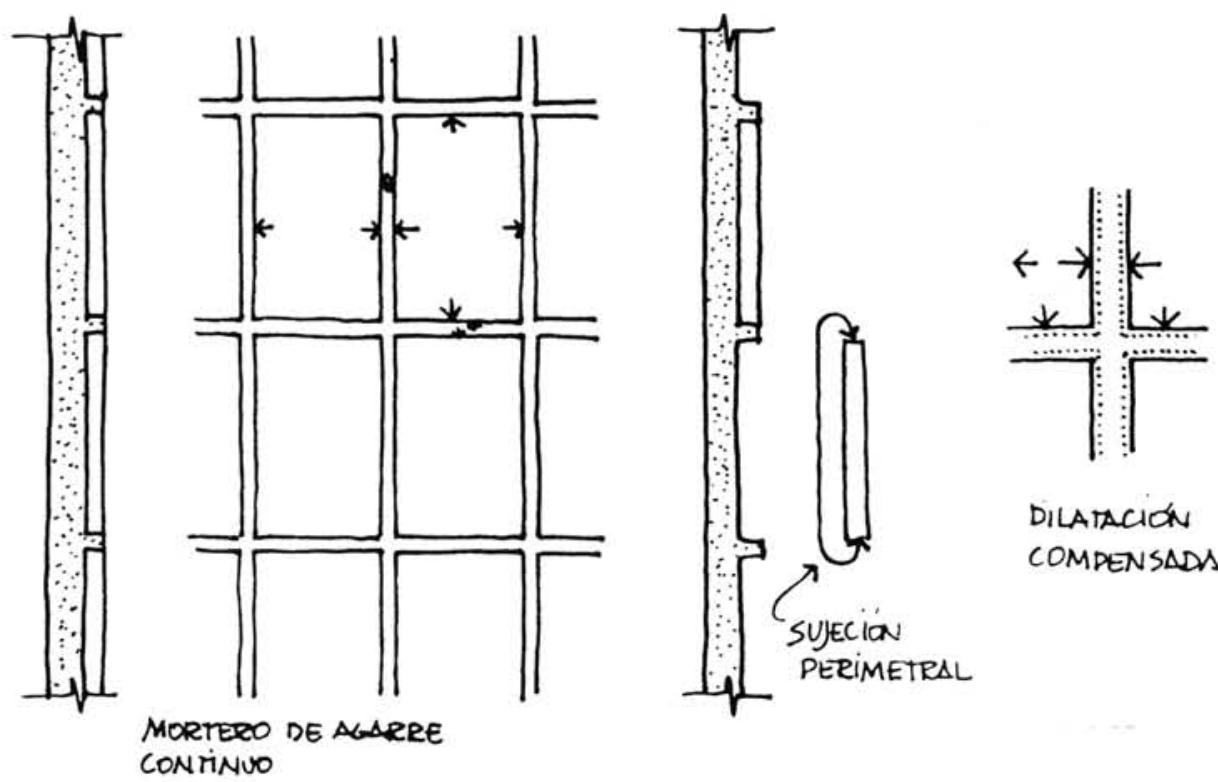

dilatación COMPENSADS

Fig. 7.b.-Alicatado con junta abierta.
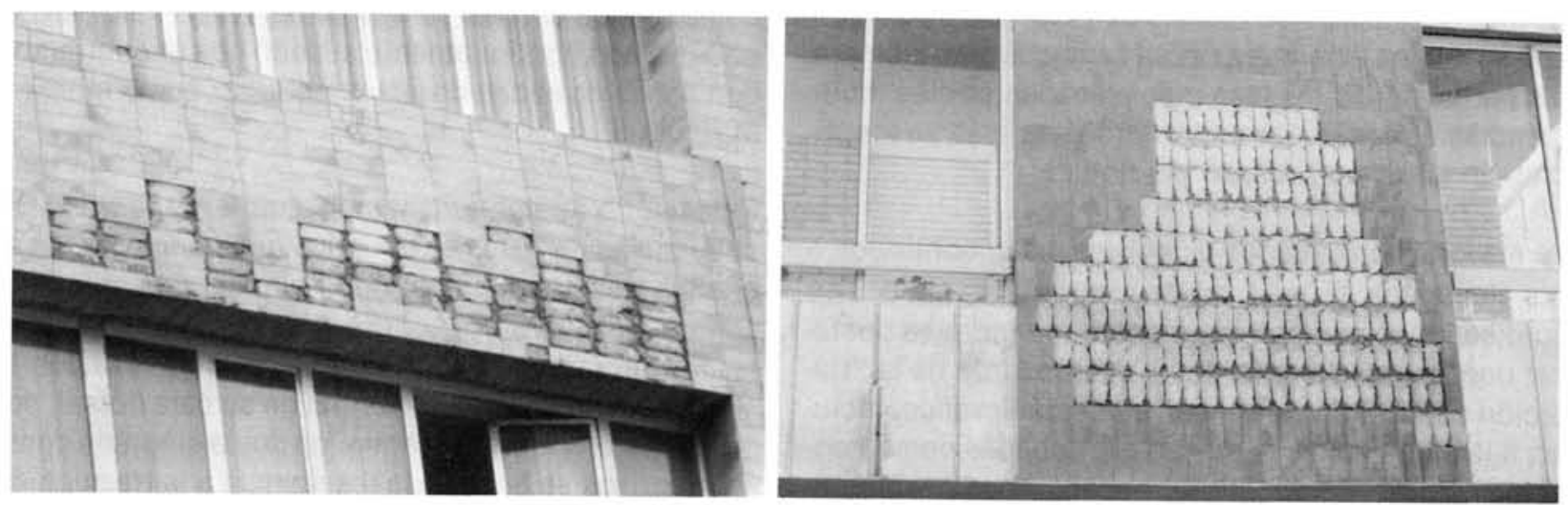
lieves de la plaqueta, lo que, evidentemente, es muy poco. Cualquier esfuerzo rasante por el movimiento relativo de la plaqueta con respecto al mortero es capaz de romper esta adherencia, y estos movimientos se dan continuamente, bien por dilataciones y contracciones térmicas de la pieza cerámica, bien por movimientos elásticos de la estructura soporte.

- Por otro lado, las plaquetas resultan colocadas "a hueso", por lo que la dilatación que sufren al recibir la radiación solar directa se transmite de unas plaquetas a otras (dilatación acumulada) por lo que las plaquetas extremas sufren movimientos relativos importantes, rompiendo fácilmente la pobre adherencia según veíamos en el punto anterior, produciendo el desprendimiento. De hecho, normalmente empiezan por caerse las plaquetas de los bordes. Fig. 9 .

- Por último, las juntas "a hueso", a pesar de la lechada superficial que las rellena, tienden a quedar abiertas después de las primeras dilataciones y contracciones. Son aberturas normalmente inferiores al milimetro, pero suficientemente amplias para permitir el paso del agua de Iluvia.

Dicha agua, al pasar al otro lado de la pieza, se encuentra con un espacio hueco por discontinuidad del mortero, según vimos anteriormente, por lo que resbala por el dorso de la plaqueta almacenándose en la junta superficial entre mortero y pieza. Al llegar las bajas temperaturas, el agua hiela y, por aumento de su volumen, actúa de cuña que vence la adherencia y produce el desprendimiento.

En definitiva, pues, tenemos dos errores sistemáticos de diseño y ejecución que acaban en desprendimiento: la discontinuidad del mortero de agarre (ejecución) y la junta "a hueso" (diseño).

Evidentemente, la solución pasará por corregir los dos. La figura 7.b muestra la solución, normalmente empleada en los países del norte de Europa desde antiguo, y que corrige los tres fallos constructivos apuntados:

- Por un lado, el mortero aplicado sobre la pared soporte, y no en el dorso de la plaqueta, tiene continuidad en las juntas y, no sólo tiene más superficie de contacto (de adherencia), sino que además "abraza" la plaqueta por sus cuatro lados, mejorando la adherencia por rozamiento.

Asimismo, evita los huecos que facilitaban (por descompresión) la entrada de agua exterior.

- Por otro, la dilatación individual de cada plaqueta es absorbida, en gran medida, por el mortero de la

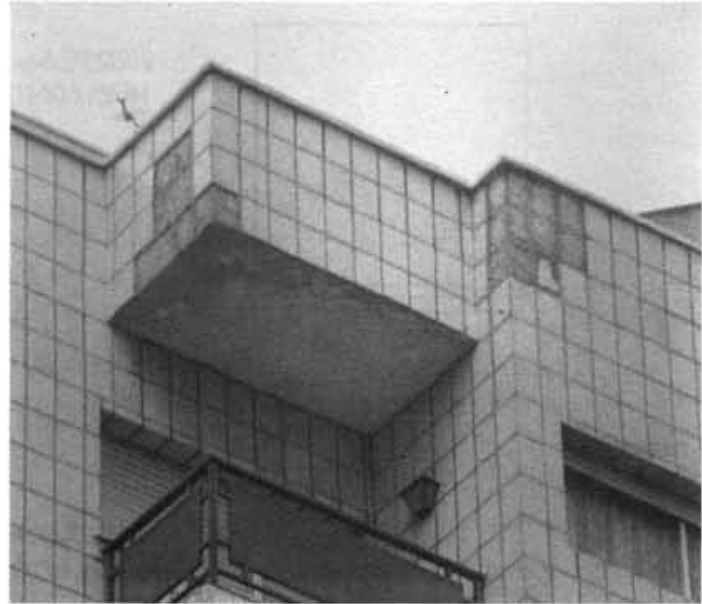

Fig. 9

junta que es, definitivamente, más blando que la propia pieza y, por tanto, más compresible, lo que evita, o disminuye, la "dilatación acumulada" mecionada con anterioridad. En realidad, cada pieza tiene una actuación más independiente en lo que se refiere a los movimientos térmicos.

- Por último, la junta de mortero dificulta la entrada del agua, sobre todo gracias a la continuidad del mismo en todo el dorso y, por tanto, a la ausencia de "cámaras de descompresión" que tienden a absorber el agua. En cualquier caso, si el agua entra, hiela y dilata, para el desprendimiento de la pieza tendrá que vencer el "agarre" lateral de las plaquetas, lo que, evidentemente, aleja la posibilidad de dicho desprendimiento.

\subsection{El hueco de ventana y su antepecho}

En ocasiones, hay detalles que parecen nimios y que, sin embargo, tienen consecuencias muy aparentes. Es el caso del encuentro entre las jambas de un hueco y el alféizar o vierteaguas del mismo, o de los churretones y ensuciamiento general de los antepechos. Veamos dos detalles concretos que suponen un descuido sistemático en el diseño constructivo.

\subsubsection{Vierteaguas con "bigotes" (Fig. 10)}

Cuando la carpinteria de un hueco de ventana no está enrasada por su exterior, aparece en su alféizar un antepecho, de material más o menos impermeable que, entre otras funciones, tiene la de "escupir" el agua de Iluvia hacia el exterior.

Su ejecución se suele materializar con una pieza plana, o un conjunto de ellas, con una inclinación hacia afuera más o menos pronunciada. Según dicha inclinación, el agua, en combinación con el viento (normal- 


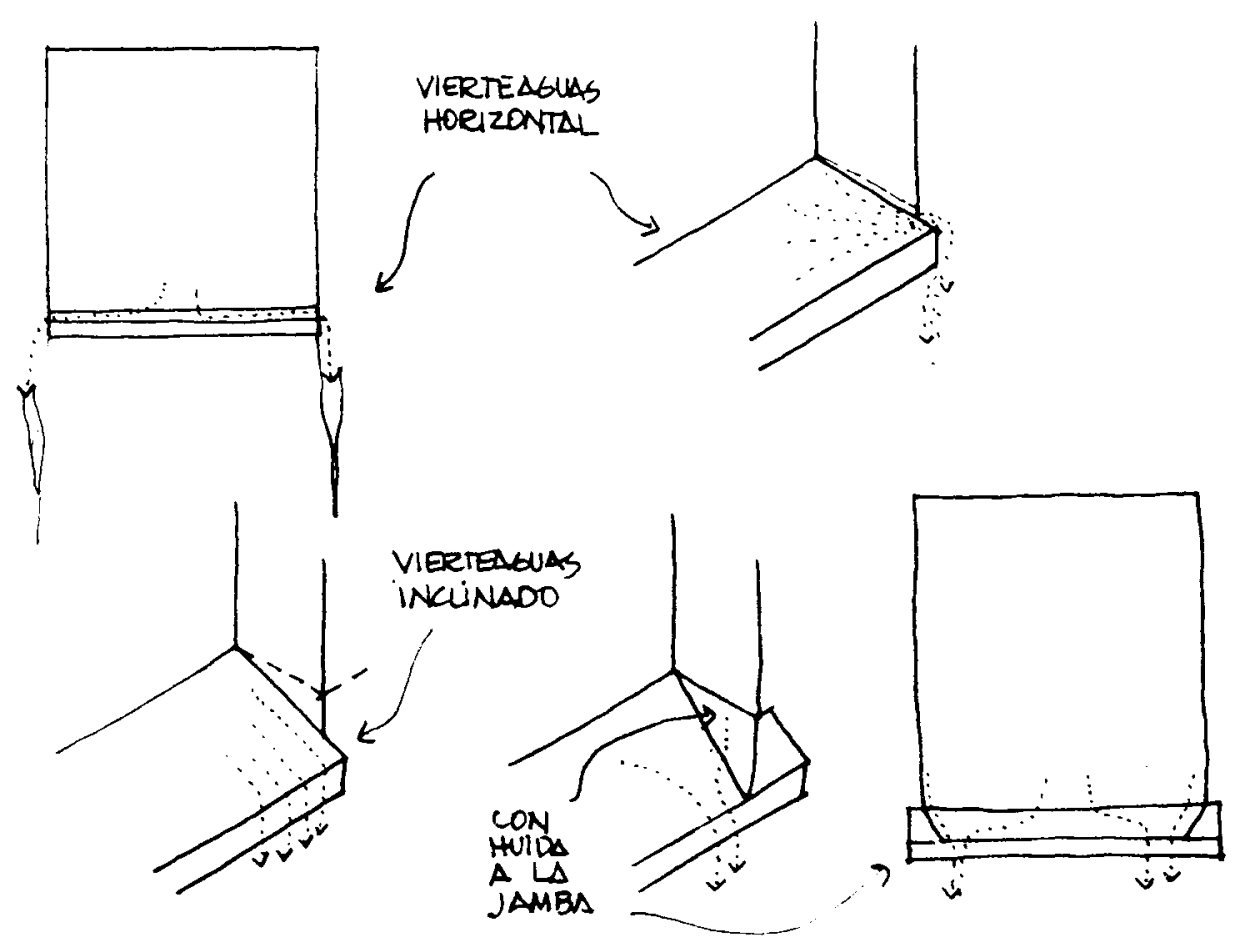

Fig. 10.-Vierteaguas con "bigotes".

mente contra la fachada) tenderá a discurrir en diversas formas. Si la inclinación es importante ( $\geq 20 \%$ ) el agua saldrá, en cualquier caso, por el borde frontal del vierteaguas, y si éste tiene un vuelo adecuado y su correspondiente goterón, el funcionamiento será correcto y no se producirán churretones sucios ni limpios. Sin embargo, si la inclinación es pobre (es, desgraciadamente, el caso más frecuente por "práctica habitual") el agua de lluvia tenderá a discurrir por los bordes interiores del vierteaguas, yendo hacia las jambas del hueco, bien por tensión superficial, bien por presión del viento. El agua tenderá a salir del hueco por los laterales del vierteaguas, pegada a la fachada, con la consiguiente acumulación de escorrentía y, por tanto, la aparición de un lavado diferencial que provoca lo que yo denomino "bigotes" que tanto afean la mayoria de las fachadas (Fig. 11).

Es éste un detalle que normalmente "no preocupa" cuando se diseña una ventana y que, sin embargo, tiene una fácil solución, con múltiples variantes. Me permito indicar dos de ellas:

- Aumentar la inclinación del vierteaguas (por encima del $20 \%$ ).

- Crear lo que llamo una "huida a la jamba", con el fin de facilitar la escorrentia por la parte central del vierteaguas, haciendo que éste tenga en los laterales una inclinación hacia el centro suficiente. Ello nos ayuda, además, a evitar posibles filtraciones por la junta casi horizontal entre jamba y vierteaguas.

\subsubsection{Ensuciamiento de los antepechos "multiplano"} (Fig. 12).

Siguiendo con el problema de la escorrentía del agua de lluvia en los huecos de ventana, independientemente de la solución del vierteaguas del alféizar, el agua no desaparece una vez que ha sobrepasado el borde frontal de ese elemento constructivo.

Comoquiera, por otra parte, que el alféizar, al ser una superficie más o menos horizontal, tiende a acumular mayor depósito de suciedad ambiental que el resto de la fachada (suciedad de contaminación) el agua, al salir del alféizar, va cargada con partículas sucias (por lo menos en la primera fase de una lluvia) que tienden a depositarse en la parte de la fachada donde el agua derrama con más lentitud y la textura esté sin empapar y sea lo suficientemente porosa.

Estas circunstancias suelen coincidir en la mayoria de los antepechos de ventana resueltos con materiales pétreos (ladrillo, hormigón, mortero de revoco, etc.). Por ello, cuando este antepecho se resuelve con distintos planos inclinados con respecto a un eje horizontal ("multiplanos") sin los necesarios goterones, aparecen los problemas de churretones limpios y sucios que ahora veremos.

Si el agua que proviene del alféizar no encuentra discontinuidad en su borde, pasa directamente al frente del antepecho, pero no lo hace de un modo uniforme, sino que, por la rugosidad de éste y por la diferente acu- 

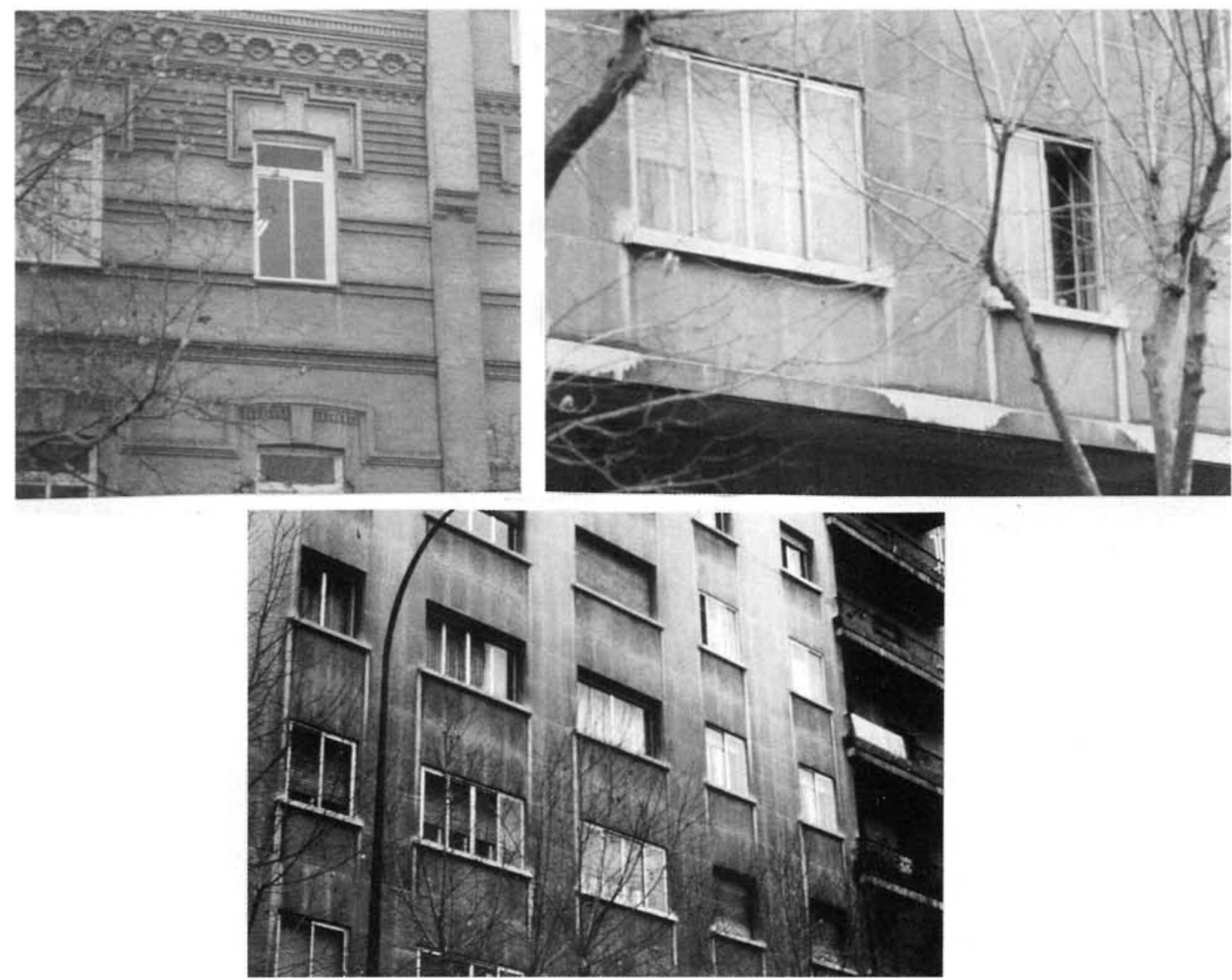

Fig. 11
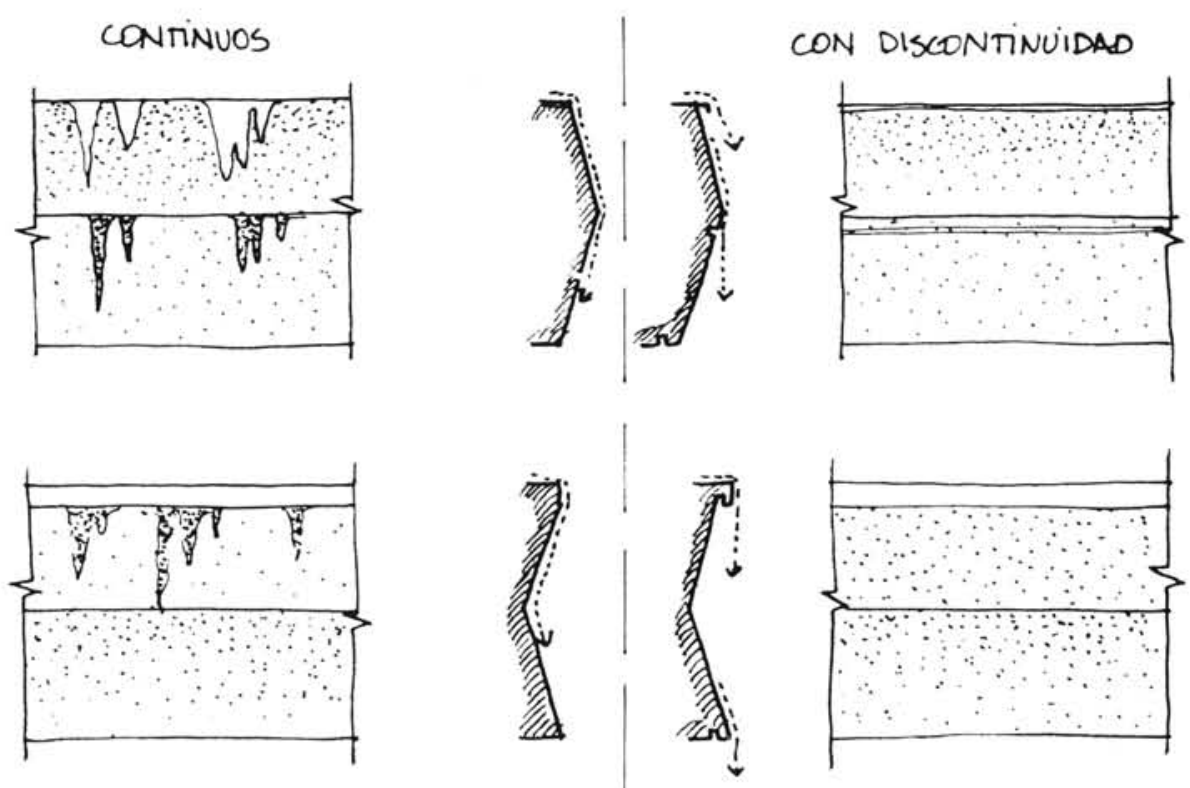

Fig. 12--Antepechos multiplanos. 

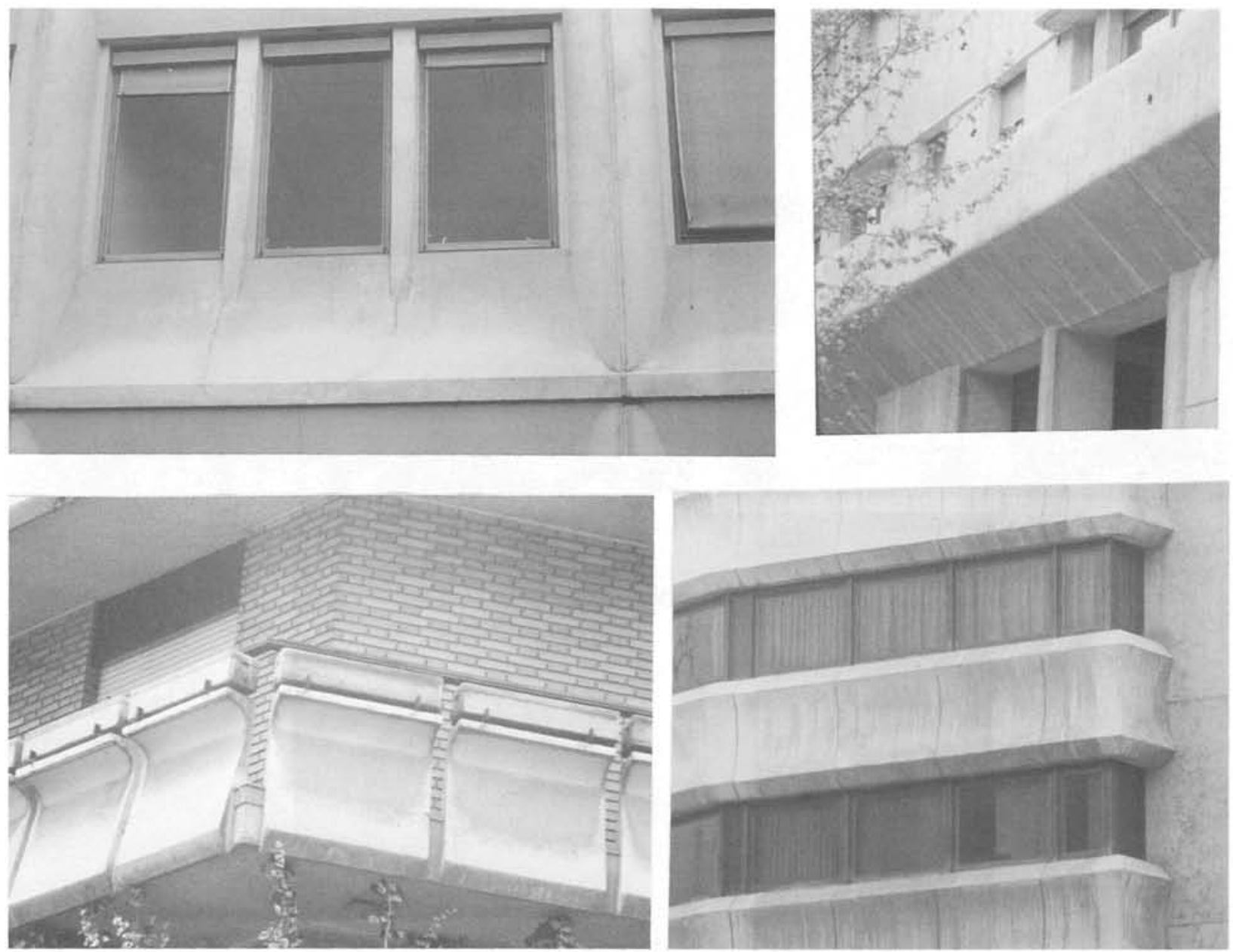

Fig. 13

mulación de la escorrentía, se distribuye en churretones. Estos churretones suelen ser "limpios" (lavado diferencial) ya que llevan abundante agua, y no sólo no permiten el depósito de las partículas de suciedad en su primera fase, sino que además arrastran las que pudieran haberse depositado en período seco, limpiando la superficie.

$\mathrm{Si}$, en su recorrido descendente, el agua se encuentra con otro cambio de plano, pasando a uno inclinado hacia abajo (cosa harto frecuente) sin ninguna discontinuidad, se produce un nuevo churretón, aunque esta vez probablemente sucio, debido a la forzosa disminución de la velocidad del agua que ahora sí permite el depósito de las partículas que arrastra.

Hemos hablado de un caso hipotético de plano inclinado hacia arriba, seguido de otro inclinado hacia abajo. Es un caso frecuente, pero no es el único. Las fotos de la figura 13 muestran, además, algún caso de planos invertidos o de superficie curvas donde el problema es similar.

En cualquier caso, la solución está, evidentemente, en introducir las discontinuidades suficientes (goterones) en los cambios de planos como para obligar al agua de escorrentía a saltar hacia afuera evitando el churretón. No obstante, en al gunos casos estos goterones no impiden siempre el que el agua vuelva a la fachada produciendo nuevas zonas de lavado. Entonces, y también con carácter general, tenemos todavia el recurso de utilizar materiales compactos y pulidos (poco porosos) para la ejecución de esos antepechos. Es un caso muy claro en zonas donde la contaminación es muy fuerte y el nivel de protección es alto (bajo nivel de exposición).

Aun así, este problema del ensuciamiento de antepechos no tiene soluciones generales, pues en algunos casos podrá ser aconsejable no introducir goterones entre vierteaguas y antepecho. Es lo que ocurre en huecos con alto nivel de exposición en los que la fuerza de limpieza del agua de lluvia, ayudada por el viento, es tan alta que es mejor que el agua discurra sin interrupción para facilitar la limpieza. Pero entramos entonces en un análisis más pormenorizado del problema del ensuciamiento de fachadas, que no corresponde a este artículo. 


\subsection{Patologia de las molduras horizontales (Fig. 14)}

Es este un elemento constructivo ya algo anacrónico que, sin embargo, ha supuesto una ayuda importante para la composición estética de las fachadas de nues. tros edificios en el siglo pasado y principios de éste, debido, inicialmente, a la solución constructiva de los frentes de forjado, y que cobra importancia de nuevo por dos razones básicas: por un lado, por la conservación del patrimonio arquitectónico y su restauración; por otro, por el mimetismo tan de moda que lleva a recuperar este tipo de elementos en las fachadas que, en cualquier caso, ayudan a su composición formal.

Tanto en uno como en otro caso (restauración o nueva ejecución) resulta evidente el error sistemático que se produce en su diseño y ejecución, que provoca la aparición de un proceso patológico con, por lo menos, dos lesiones constructivas evidentes, apuntadas a continuación: humedades y ensuciamiento.
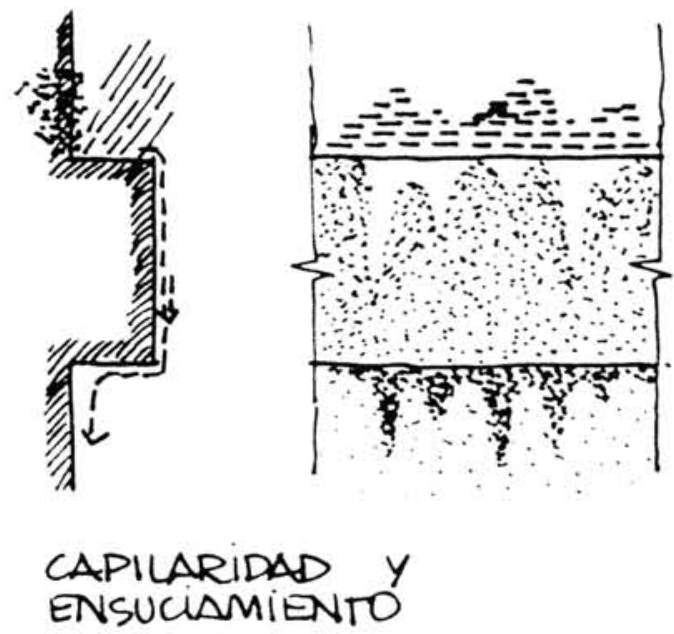

Por un lado, como elemento saliente de la fachada, está más expuesto a los agentes atmosféricos y necesita, por tanto, mayor protección; habrá que proteger, es. pecialmente, su plano superior (horizontal).

Pero esta protección, a base de algún tipo de material impermeable (baldosas, láminas, etc.) que normalmente se prevé, no se puede colocar de cualquier manera, pues según cómo, puede permitir humedades de capilaridad.

En efecto, si ese babero es horizontal, el agua de lluvia (directa y por escorrentía de la pared superior) que sobre él se acumula, ayudada por el viento, tiende a penetrar en la junta entre los dos planos, al igual que veiamos en los zócalos, y si el acabado de la pared es po. roso (caso muy frecuente de revocos y ladrillos) dicha agua tenderá a ascender por capilaridad provocando, además, eflorescencias y posteriores erosiones y desprendimientos (ver fotos figura 15).
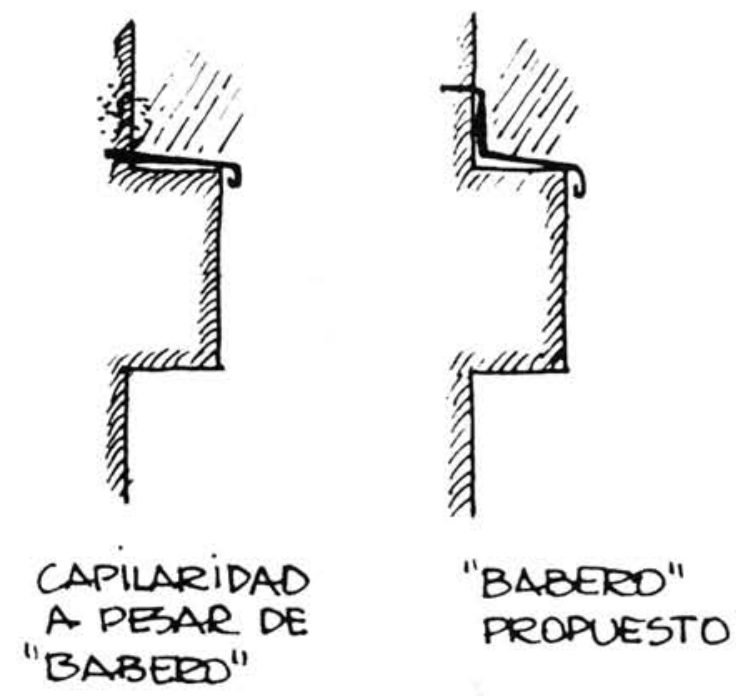

Fig. 14.-Moldura horizontal.

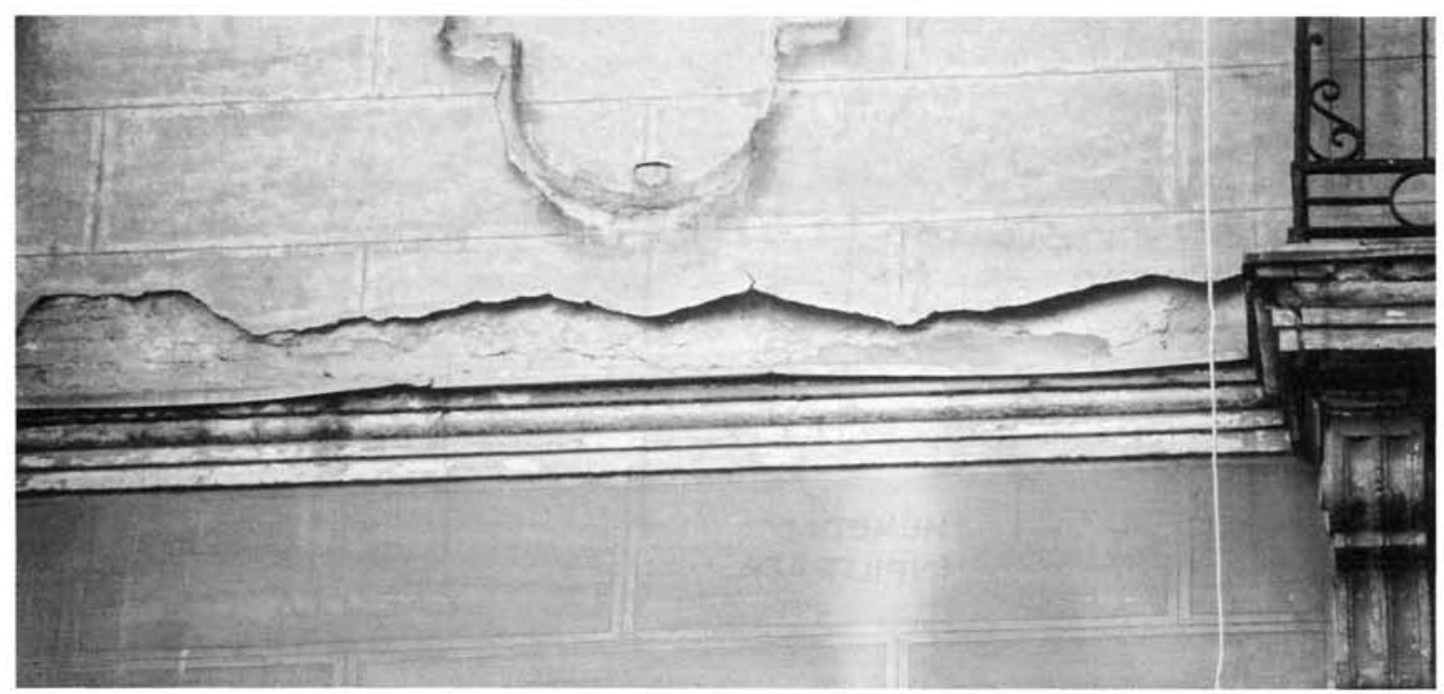

Fig. 15 
Este problema es relativamente fácil de resolver, bien aumentando la inclusión del babero, bien, sobre todo en el caso de revocos y con baberos de chapa, subiendo unos $5 \mathrm{~cm}$ este babero de chapa para evitar la filtración del agua, tal como indica la figura 14.

Por otro lado, como segunda lesión apuntada en las molduras horizontales, aparece su ensuciamiento por el hecho, sobre todo, de los cambios bruscos de planos en un elemento saliente.

El problema es similar al mencionado para los antepechos por la falta de goterones que rompan la continuidad de los diedros y eviten los churretones, aunque en este caso cuando se trate de molduras de poca "potencia" (altura) puede ser suficiente con el goterón en el primer cambio de planos a base del vuelo suficiente del babero superior. Sin embargo, cuando la moldura sea más importante o esté "historiada" (molduras múltiples) habrá que estudiar los saltos de plano con más cuidado e introducir los goterones que se estimen convenientes.

\subsection{Patología de los balcones}

Estamos, de nuevo, ante un elemento saliente de la fachada, esta vez más importante que la simple moldura $y$, por tanto, con una patología mucho más amplia.

El ataque de los agentes atmosféricos se recrudece y, por tanto, las medidas de protección tienen que vigilarse más. De entre los múltiples detalles constructivos que aparecen con posibilidades de lesión, me interesa destacar dos que, como en otros casos, presentan un ejemplo claro de error sistemático, tanto en su diseño (o falta del mismo) como en su ejecución. Veamos:

\subsubsection{Drenaje con peto de obra (Fig. 16)}

Cuando la barandilla del balcón se resuelve con murete de obra (o, por lo menos, su parte baja) hay una solución, casi implícita, de su drenaje mediante gárgola directa al exterior. Dicha gárgola, en la mayoría de los casos, es un simple tubo metálico de reducida sección (de unos $3 \mathrm{~cm}$ de diametro) que arranca en el mismo borde del pavimento y suele tener poca inclinación y poco vuelo (ver fotos Fig. 17).

El resultado funcional es la obstrucción inmediata de la boca del tubo, o su saturación en un momento de gran afluencia de agua, y la filtración de ésta por sus bordes en el espesor de peto. En ocasiones, incluso, el agua llega a salir por el tubo, pero por su superficie exterior a través del muro. El proceso patológico genera, además de las propias manchas de humedad, las consiguientes eflorescencias y erosiones físicas (Fig. 17).

La cuestión fundamental está en que no se tiene en cuenta que el balcón con peto de fábrica se convierte en una cubeta que hay que tratar y desaguar como tal. Es decir, en primer lugar, impermeabilizar la base de sus paredes hasta el posible nivel del agua (por lo menos $15 \mathrm{~cm}$ ) y, a continuación, realizar el drenaje dando continuidad al material impermeable con la boca del tubo drenante, de manera que en su encuentro no se puedan producir filtraciones. Lo lógico es introducir una cazoleta sumidero entre el pavimento y la gárgola, al igual que se hace para el drenaje de cualquier cubierta plana cuando se llevan las aguas a una bajante (ver Fig. 16). Al fin y al cabo una gárgola es, desde el punto de vista funconal, como el inicio de una bajante. Asi está tratada, por ejemplo, el caso de la foto de la Fig. 18).
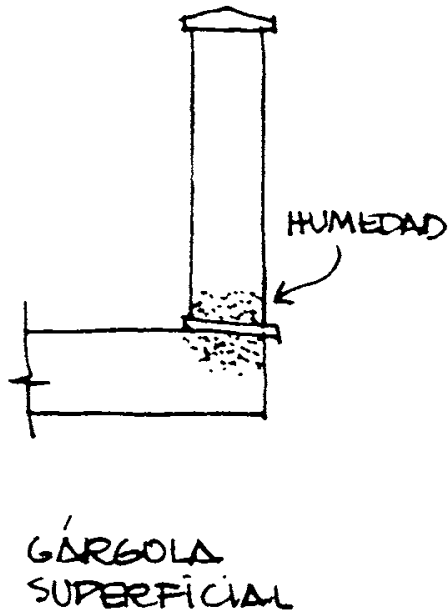

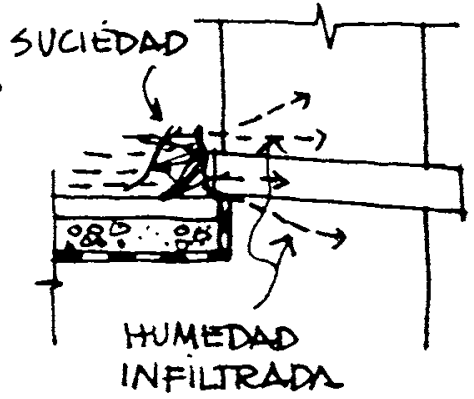

INFILTRADS

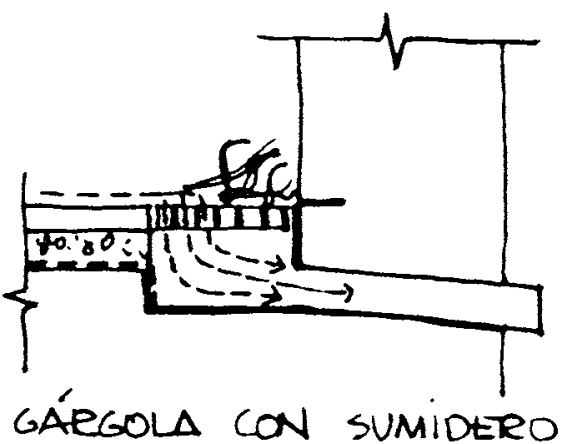

Fig. 16.-Drenaje de balcón. 

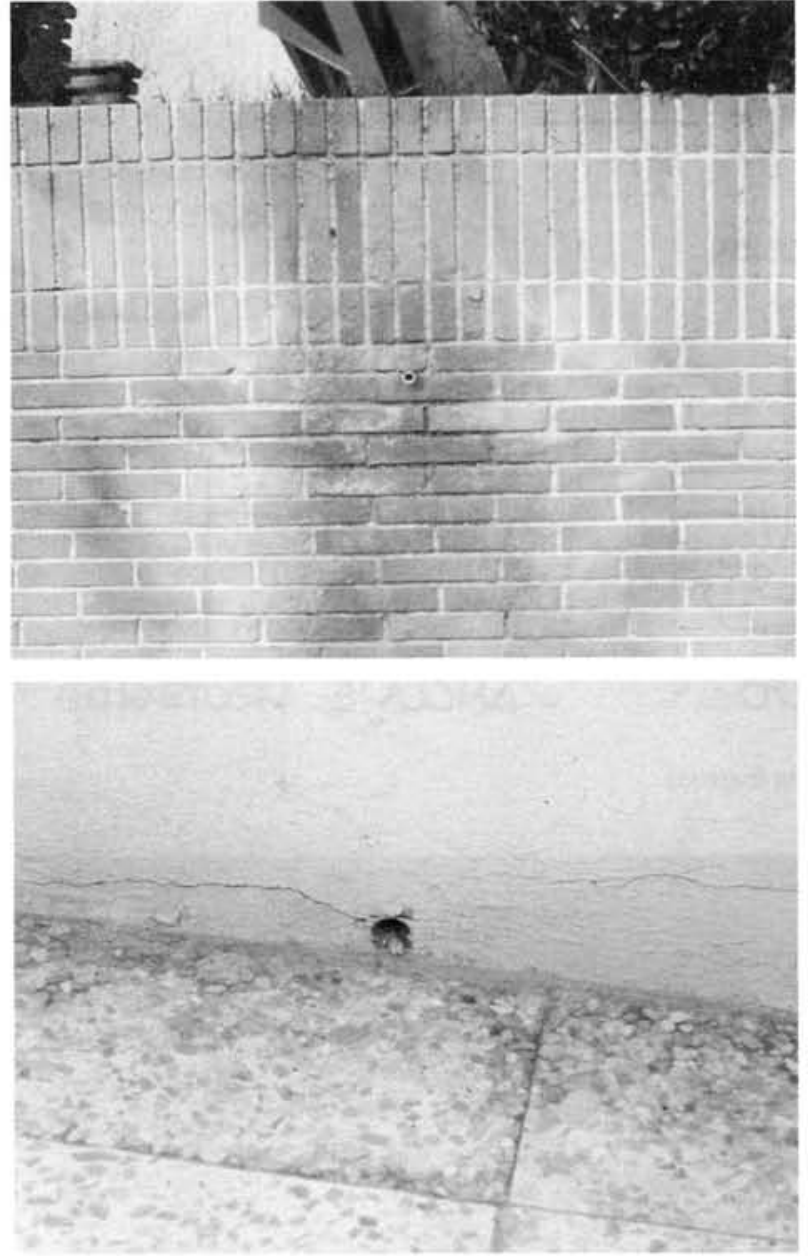

Fig. 17

\subsubsection{Anclajes de barandillas metálicas (Fig. 19)}

Cuando la barandilla se resuleve con elementos metálicos anclados al propio balcón volado o a las paredes de la fachada, existe, entre otros, un punto conflictivo clave, olvidado normalmente del diseño, y con su consiguiente proceso patológico. Me refiero a los anclajes, tanto verticales, como horizontales.

El anclaje de un elemento metálico en un muro de fábrica, partiendo del supuesto de que se realiza bien, es decir, anclando al muro propiamente dicho y no a su acabado, no deja de ser una herida en el muro que tiende a permanecer abierta por los distintos coeficientes de dilatación de los materiales que se unen puntualmente. En efecto, a los primeros cambios de temperatura, se abre una fisura entre la barandilla y el mortero que la "agarra", fisura por la que tiende a entrar el agua que se queda en contacto con la pieza metálica y, por "inmersión" la corroe, destruyéndola (Fig. 20).

Por otra parte, el encuentro entre los dos elementos produce un diedro de $90^{\circ}$ que facilita la acumulación de agua y suciedad, que mantiene húmeda la zona del encuentro cuando el resto está seco produciendo, por "aireación diferencial", un nuevo proceso de corrosión. 

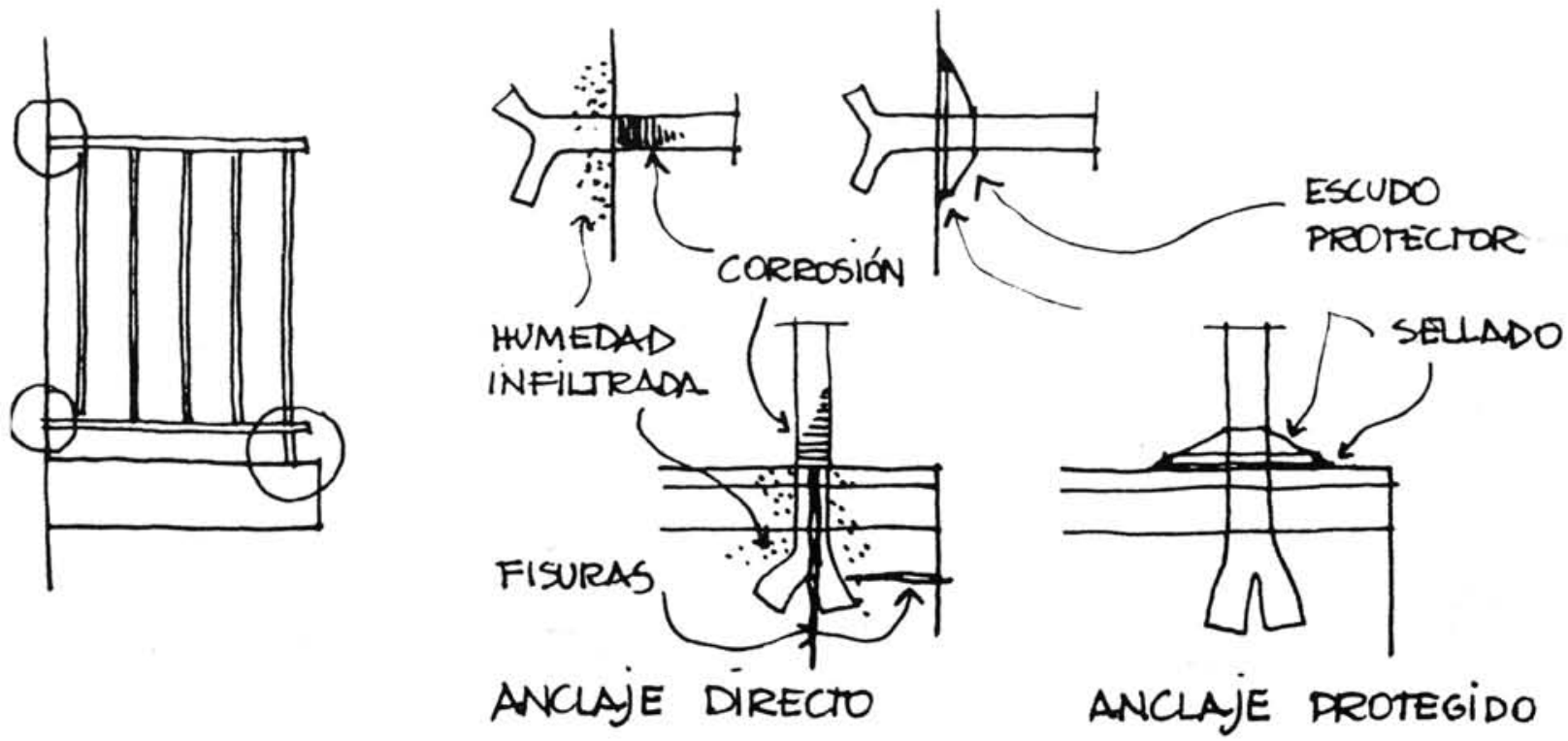

Fig. 19.-Barandilla metálica.
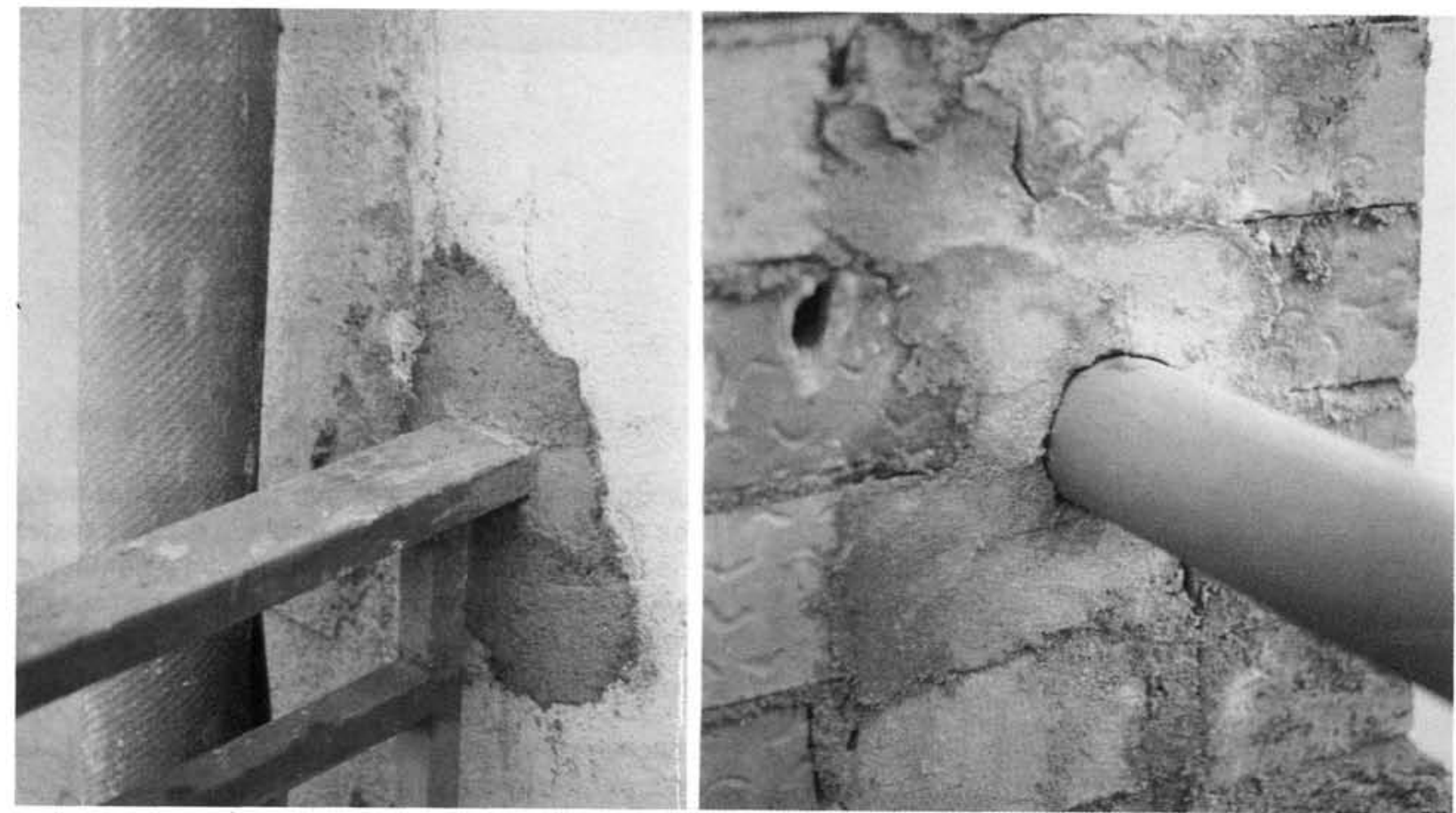

Fig. 20

Ambos problemas se producen tanto en anclajes horizontales (sobre pared vertical) como en los verticales (sobre pavimento o remate superior de peto) aunque resultan evidentemente más acentuados en estos últimos por la amplia plataforma horizontal que facilita la acumulación del agua y su posterior filtración. No extraña así la antigua costumbre de preferir los anclajes horizontales a los verticales e, incluso, eliminar éstos, como se puede observar en los balcones metálicos de nuestro patrimonio arquitectónico.
En cualquier caso, se trata, pues, de "tapar" la fisura entre metal y mortero para que no se filtre el agua, y reducir en lo posible el "rincón" que se produce entre ambos elementos para dificultar la acumulación de humedad en él. Ambos propósitos se pueden alcanzar (Fig. 19) mediante el uso de "escudos" protectores, que actúan como tapajuntas funcionales, evitan la acumulación de humedad y, a la vez, mejoran el aspecto estético indicando un mejor remate constructivo de la unidad. 
Con esta solución, ya bastante en uso, aunque no lo suficiente, pueden ser admitidos, incluso, los temidos anclajes verticales.

\subsection{Cornisa de cubierta plana}

Por último, y aunque entremos ya en el plano de la cubierta, no quiero dejar de mencionar un problema patológico que aparece con demasiada frecuencia en las cornisas de los edificios resueltos con cubierta plana y peto de obra y que se debe a un nuevo error sistemático de diseño y de ejecución, error que se acepta como solución posible incluso en las NTE. Me refiero a las humedades de filtración en esa línea horizontal que acaban, además, con consabidas eflorescencias y erosiones físicas (ver fotos Fig. 21).

El error parte de olvidar las fuertes dilataciones y contracciones que sufre, por radiación solar directa, el ta-
Por esa razón, el tablero debe ser siempre independiente del peto y, sin embargo, en muchos casos y, sobre todo, cuando se coloca hormigón celular de pendiente, se olvida esta independencia, por lo menos a la hora de colocar la membrana impermeable, a la que se da continuidad entre tablero y peto, según se ve en la Fig. 22, tomada de la NTE-QAN. Esta solución provoca la rotura de la tela en su borde curvo inferior, a pesar de la elasticidad de la misma, elasticidad que, en cualquier caso, pierde con el soleamiento directo.

Por otra parte, hay que indicar que ese refuerzo de membrana, indicado en la norma como QAN-5, en la práctica se coloca sin roza superior, simplemente adherido, lo que agrava el proceso patológico al despegarse con facilidad por su borde superior.

La solución aparece también en la misma norma, cuando indica el detalle para canalón perimetral o para faldón sobre tabiquillos ${ }^{4}$ (Figs. 23 y 24). En cualquiera
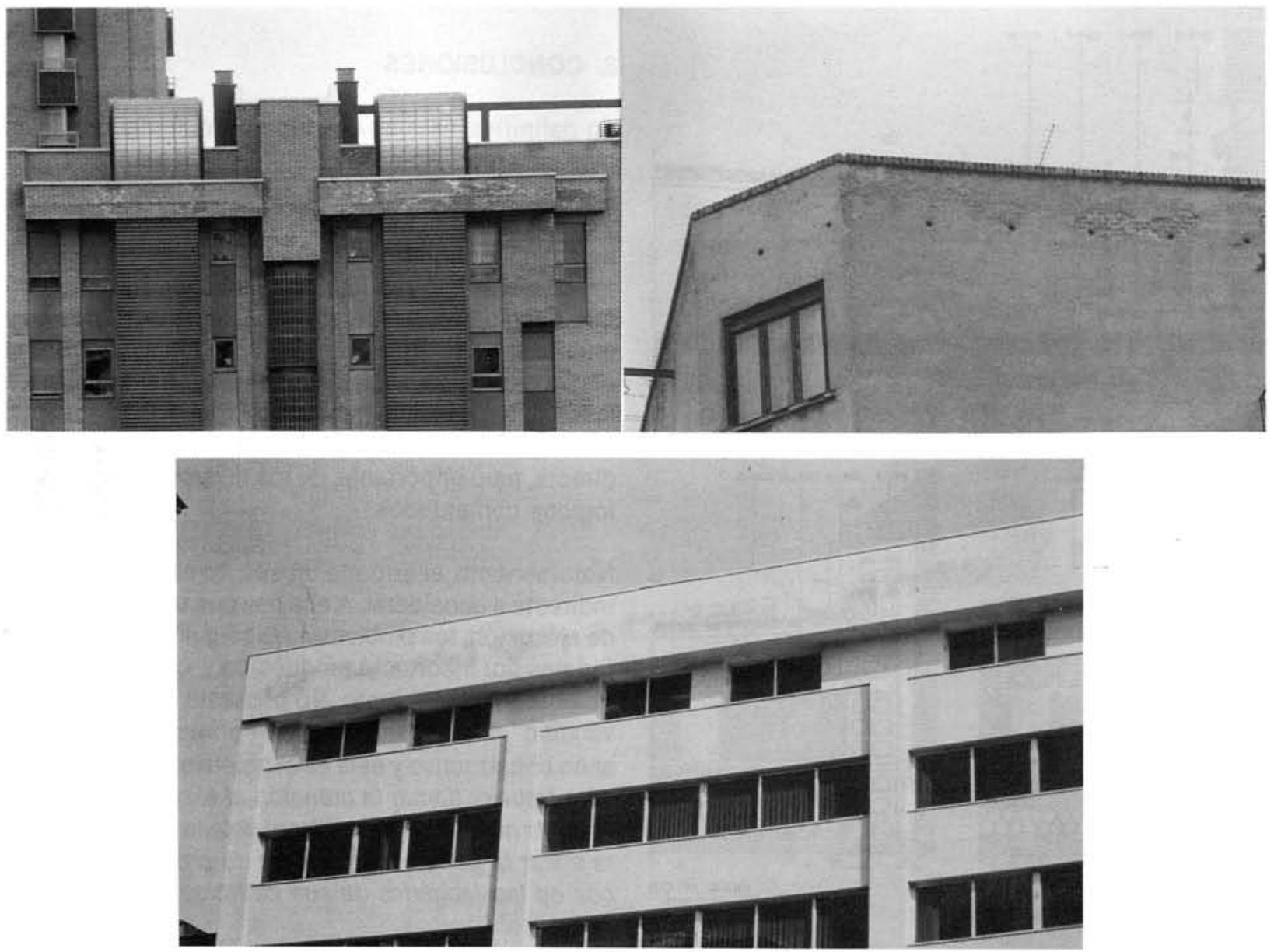

Fig. 21

blero de una cubierta plana, dilatación y contracción que son independientes de las del peto y que hace que ambas unidades constructivas (tablero y peto) se separen mucho entre si en la contracción, en función de la temperatura que alcanza y del tamaño de la cubierta.
${ }^{4}$ Aunque esto pertenece al tema de cubiertas, no quiero dejar de mencionar el error que supone la formación de faldones con hormi. gón celular y, por tanto, sin cámara de aire ventilada, por el desprecio que supone de las altas temperaturas que se alcanzan en la cubierta por la radiación solar directa. 

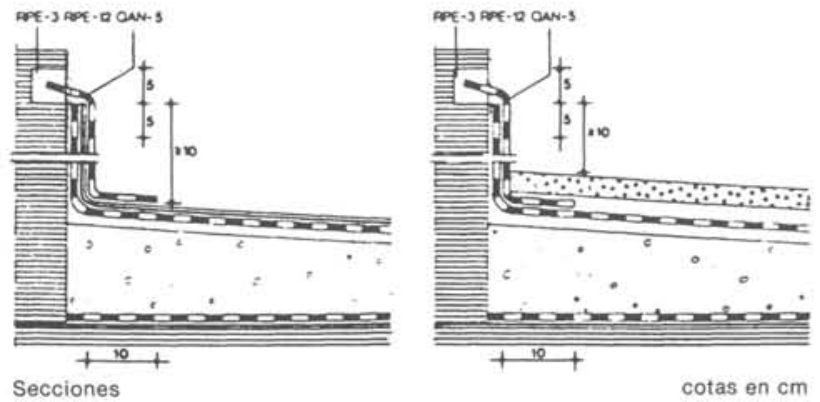

Fig. 22
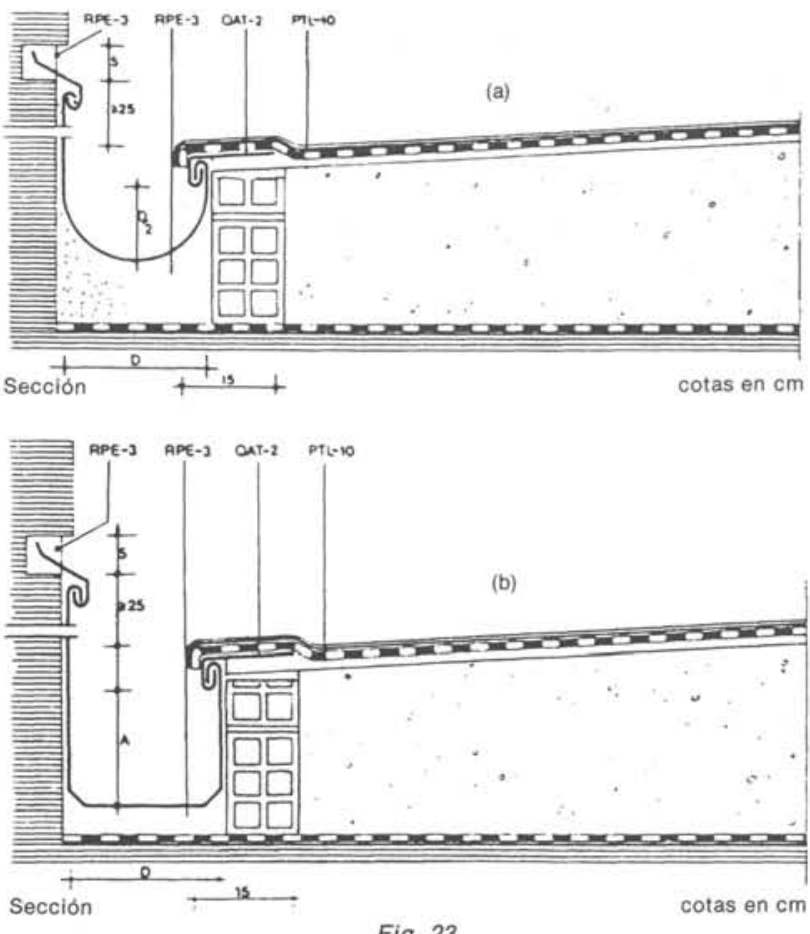

Fig. 23

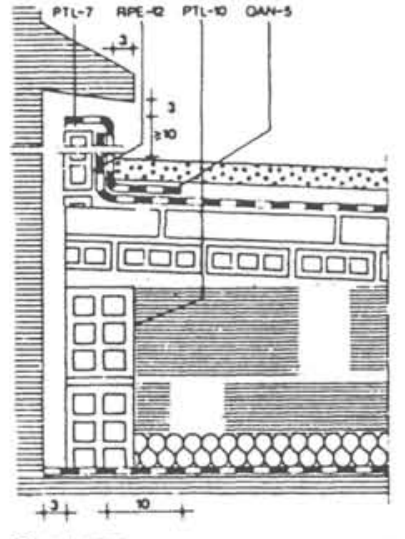

Secciones

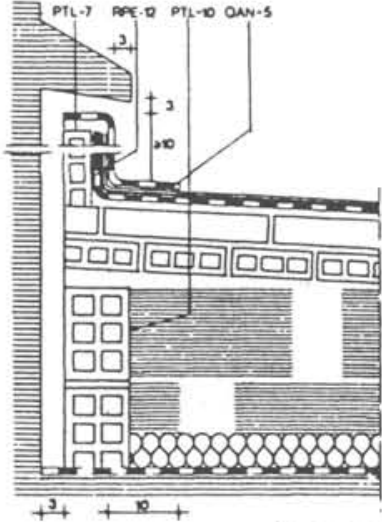

Fig. 24 cotas en $\mathrm{cm}$
Fig. 22.-Encuentro de faldón de hormigón con paramentos.

Fig. 23a.-Canalón rectangular en faldón de hormigón-D-A

b.-Encuentro de faldón sobre tabiquillos con paramentos.

Fig. 24.-Canalón circular en faldón de hormigón-D.

de los dos casos, resulta independiente el tablero superior del peto y convenientemente protegido de la posible filtración, por lo que su funcionamiento es correcto.

En cualquier caso, cabe mencionar que la solución indicada en la Fig. 24 para faldón sobre tabiquillos es perfectamente utilizable en el caso de faldón resuelto con hormigón de pendiente, por lo que también éste, a pesar de su mal funcionamiento higrotérmico, tiene solución normal en este encuentro.

\section{CONCLUSIONES}

En definitiva, esto no ha sido más que algunos ejemplos para recordar que la construcción está basada en los encuentros de unidades y materiales constructivos, y que la buena construcción ( $y$, de algún modo, la buena solución arquitectónica) está basada en el diseño adecuado de esos encuentros y detalles constructivos que, desgraciadamente, están bastante olvidados en el quehacer profesional. De hecho, en los estudios estadisticos realizados hasta el momento, se muestra una indefinición bastante generalizada del diseño constructivo de las unidades de las fachadas, que es causa indirecta, pero importante, de los diversos efectos patológicos comentados.

Naturalmente, el error de diseño no es la única causa indirecta a considerar. A ella hay que unir los defectos de ejecución, los problemas físico-químicos de los materiales por incorrecta producción y, cómo no, el insuficiente mantenimiento. No obstante, a nivel de "prevención" nos debemos fijar, en primer lugar, en el diseño constructivo y éste es el objetivo fundamental de este trabajo: llamar la atención al técnico proyectista sobre la necesidad de cuidar el detalle constructivo para evitar la peligrosa aparición de procesos patológicos en las fachadas de sus edificios. 